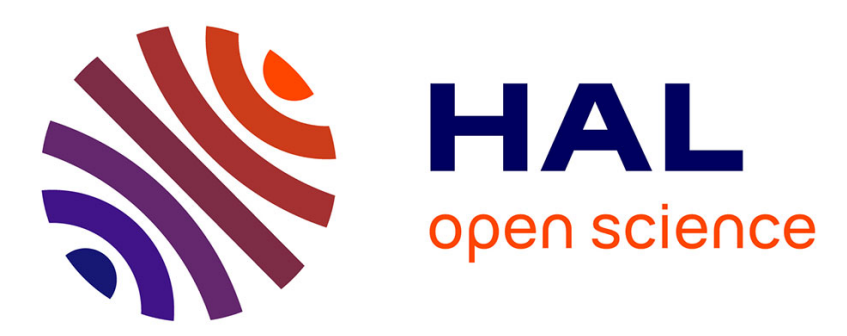

\title{
Definition of spacing constraints for the car sequencing problem
}

\author{
Aymeric Lesert, Gülgün Alpan, Yannick Frein, Stephane Noire
}

\section{To cite this version:}

Aymeric Lesert, Gülgün Alpan, Yannick Frein, Stephane Noire. Definition of spacing constraints for the car sequencing problem. International Journal of Production Research, 2010, pp.1. 10.1080/00207540903469043 . hal-00454445v2

\section{HAL Id: hal-00454445 \\ https://hal.science/hal-00454445v2}

Submitted on 16 Feb 2011

HAL is a multi-disciplinary open access archive for the deposit and dissemination of scientific research documents, whether they are published or not. The documents may come from teaching and research institutions in France or abroad, or from public or private research centers.
L'archive ouverte pluridisciplinaire HAL, est destinée au dépôt et à la diffusion de documents scientifiques de niveau recherche, publiés ou non, émanant des établissements d'enseignement et de recherche français ou étrangers, des laboratoires publics ou privés. 


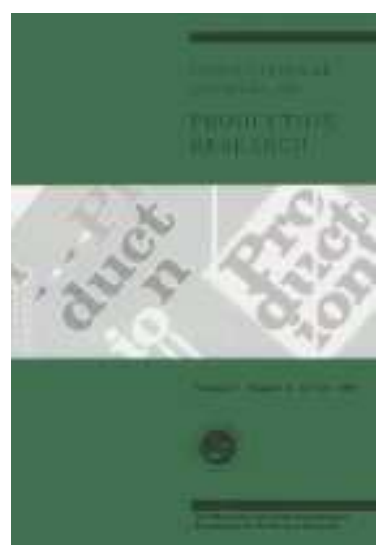

\section{Definition of spacing constraints for the car sequencing problem}

\begin{tabular}{|c|c|}
\hline Journal: & International Journal of Production Research \\
\hline Manuscript ID: & TPRS-2008-IJPR-0730.R2 \\
\hline Manuscript Type: & Original Manuscript \\
\hline $\begin{array}{r}\text { Date Submitted by the } \\
\text { Author: }\end{array}$ & 15-Jul-2009 \\
\hline Complete List of Authors: & $\begin{array}{l}\text { Lesert, Aymeric; Laboratoire G-SCOP } \\
\text { Alpan, Gulgun; Laboratoire G-SCOP, Grenoble Institute of } \\
\text { Technology } \\
\text { Frein, Yannick; Laboratoire G-SCOP, Grenoble Institute of } \\
\text { Technology } \\
\text { Noire, Stephane; PSA Peugeot Citroën }\end{array}$ \\
\hline Keywords: & ASSEMBLY LINE BALANCING, MIXED MODEL SEQUENCING \\
\hline Keywords (user): & SPACING CONSTRAINTS \\
\hline
\end{tabular}

\section{ScholarONE" \\ Manuscript Central}




\author{
Aymeric Lesert $^{2}$, Gülgün Alpan ${ }^{2}$, Yannick Frein $^{2}$, Stéphane Noiré $^{1}$ \\ ${ }^{1}$ PSA Peugeot Citroën, 45, rue Jean-Pierre Timbaud, 78307 Poissy Cedex, \\ stephane.noire@mpsa.com \\ ${ }^{2}$ G-SCOP, ENSGI-INPG,46 Avenue Félix Viallet, 38031 Grenoble Cedex,
} aymeric.lesert@wanadoo.fr, gulgun.alpan@g-scop.inpg.fr,yannick.frein@g-scop.inpg.fr

\begin{abstract}
Car sequencing problem deals with the ordering of a list of vehicles to be produced on an assembly line so that the overall capacity of each workstation is not exceeded. Some types of vehicles require several time consuming operations to be done on a workstation and will naturally overload that workstation. Such vehicles are spaced out in the sequence, by means of a set of spacing constraints, in order to cope with the momentary increase of workload that they create. Two questions arise: which type of vehicles should be subject to the spacing constraints and by which distance should they be spaced out in the sequence. In practice as well as in the car sequencing literature, there does not exist a methodical way to answer the first question and the existing methods for the second one is no longer adequate due to the increased diversity of cars produced in an assembly line. In this paper, we propose two new methods to answer these questions with a special emphasis on the first one. The performance of the proposed methods is illustrated using a real case study.
\end{abstract}

KEYWORDS: Spacing constraints, mixed model assembly lines, line balancing, car sequencing problem, automotive industry 


\section{Introduction}

A typical automotive assembly line is physically divided into more than a hundred consecutive workstations. In each workstation, one or more operators perform a number of tasks on each vehicle (see figure 1) using the parts and tools available. Every vehicle to be produced goes through these serial workstations at the same speed and in the same order. Due to this constant velocity, these assembly lines are also called the paced assembly lines. Time spent by a vehicle in a workstation is called the cycle time. Physically this means that when the $j^{\text {th }}$ vehicle in the sequence exits a given workstation the $(j+1)^{s t}$ vehicle enters it and spends a time equal to the cycle time in this station (see figure 1).

Assembly line balancing consists in assigning the operations to the workstations such that the workload of each station is the most homogenous possible and the average time of the tasks to be performed in every workstation does not exceed the cycle time (Scholl and Becker, 2006), (Becker and Scholl, 2006). In practice, for economical and technical reasons, duration of some type of vehicles is allowed to exceed the cycle time at some. These vehicles overload the related workstation since the operator needs more than the cycle time to complete the tasks on the vehicle. The operator accumulates a delay since he now has less than the cycle time to finish the next vehicle. If the following vehicles have high operation durations as well, the operator cannot recover the delay. If the total delay becomes important and no recovery is possible, either a utility worker is called up for help or the line is stopped.

\section{[FIGURE 1 HERE]}

These emergency solutions are costly and may also degrade the product quality. In practice (Comby, 1996), (Baratou, 1998), (Joly, 2004), (Bernier and Frein, 2004), (Joly et. al. 2008) as well as in the car sequencing literature (for example, see (Burns and Daganzo, 1986), (Tsai, 1992) and (Warwick and Tsang, 1995)) the vehicles which create overload are spaced in the sequence. This is realized by spacing constraints.

A spacing constraint is defined by two data: a criterion and a ratio N/P. The criterion represents an option or a combination of several options to be spaced. The ratio N/P represents the maximum number (i.e. $\mathrm{N}$ ) of vehicles with the criterion in a sliding window of (P) vehicles in the sequence. If this ratio is well chosen and a sequence respecting the spacing constraint is found, total utility work is minimized (Bolat and Yano, 1992a, 1992b). The literature on the car sequencing problem is abundant. Here, we will not give a detailed 
overview of this literature but we invite the interested readers to refer to the recent surveys by (Solnon et. al., 2007) and (Boysen et. al. 2009) which give a complete review of the existing work.

The existing literature which deals with the car sequencing problem assume that the spacing constraints are given and correctly defined. However, the quality of the car sequence is highly dependent on a correct definition of the spacing constraints (Bolat and Yano, 1992b). In practice, the criteria of the spacing constraints are defined based on experience and the ratios, N/P, are often deduced by the number of vehicles to produce. In the current context of the automobile industry, the diversity of vehicles which can be produced on a mixed model assembly line is tremendous and the definition of spacing constraints is a very complicated task (Lesert and al., 2007). To the best of our knowledge, no work exists in the literature on the selection of the criteria of the spacing constraints and very few studies have been reported on the calculation of N/P (Giard and Jeunet, 2006), (Yano and Rachamadugu, 1991), (Bolat and Yano, 1992a), (Bolat and Yano, 1992b).

In this article, we will describe a model for the definition of spacing constraints to answer the following questions: which options should be spaced (i.e. definition of the criteria) and by which distance (i.e. calculation of $N_{k} / P_{k}$, where $k$ is the index of the constraint) such that the emergency situations which may occur on the assembly line are captured better by the spacing constraints. To achieve these objectives we will first analyse, in section 2 , the movements of an operator in his workstation. This analysis gives us valuable information on how an operator accumulates delay. Section 3 is dedicated to the definition of the criteria of the spacing constraint while section 4 describes how to choose the values $N_{k}$ and $P_{k}$, for all $k$. In section 5, the proposed method is compared to the current methods and its performance is illustrated via some numerical results based on generated data. Section 6 presents a real case study. Finally, section 7 concludes the article.

\section{Mathematical model of a delay}

As mentioned before, if an operator accumulates an important delay, a utility worker is called up for help. In order to model the accumulation of the delay we first observe the movements of an operator. 


\section{Movement of an operator in his workstation}

A typical automotive assembly line is a paced assembly line where the vehicles to produce move from one workstation to the other on a constant speed conveyor belt ( $x$ meters/min). In the assembly line under study, the workstations are equally sized. The time elapsed between the entry and exit of a vehicle in a workstation is hence constant and referred to as the cycle time, $T_{\text {cycle }}$. During $T_{\text {cycle }}$, a vehicle travels a distance of $x . T_{\text {cycle }}$ meters. This is the length of the workstation. Without loss of generality, we will use time metrics (e.g. $\left.T_{\text {cycle }}\right)$ to describe space limitations (e.g. $x . T_{\text {cycle }}$ ) as seen in figure 2 . Space metrics can be found by a simple conversion using the speed of the conveyor belt.

In practice, the operator may utilize a space greater than the length of his workstation. The real boundaries of workstation $i$ is hence delimited by a lower limit, $\operatorname{Min}_{i}$ and an upper limit, $\operatorname{Max}_{i}$ as shown in figure 2. $\operatorname{Min}_{i}$ and $\operatorname{Max}_{i}$ are calculated based on the technical constraints of tools used in the workstation and the specificities of the neighboring stations (i.e. the operator should not bother the neighbor operators). $\mathrm{Min}_{i}$ is always negative or null. And, $\operatorname{Max}_{i}$ is always greater than or equal to $T_{c y c l e}$. Here on, the term workspace will be used to refer to the practical boundaries of a workstation. In figure 2, the operator escorts each vehicle during the assembly task (illustrated by horizontal bars) and then walks back upstream to treat the next vehicle (illustrated by arrows). If the operator is ahead of his time, he may start working on a vehicle before it actually enters the workstation (case of vehicle 2 in figure 2). Similarly, if he has accumulated some delay, he may continue working on a vehicle beyond his own workstation (case of vehicles 2 and 3 in figure 2).

\section{[FIGURE 2 HERE]}

When an operator can not complete all assembly tasks within the workspace (case of vehicle 4 in figure 2), one of the following solutions can be used:

(i) The operator can stop the line to finish his job and restart the line afterwards (Toyota's ANDON $^{1}$ method) (see Tsaï (1992) and Kim (2001)) (ii) A utility worker can be called up to complete the unfinished work when the vehicle exits the workspace (Giard and Jeunet, 2006), (Bolat and Yano, 1992a, 1992b). (iii) The utility worker treats a complete vehicle which cannot be completed in the workspace (Giard and Jeunet, 2006).

\footnotetext{
${ }^{1}$ ANDON : little lantern (In Japanese). A warning light is switched on above the operator who stops the line.
} 
In this article, we will use the third approach since it satisfies the quality requirement that an operator, who starts an assembly task on a vehicle, completes the task to avoid some operations to be forgotten. Based on this hypothesis, the vehicle 4 in figure 2 will completely be treated by a utility worker ${ }^{2}$ as soon as it enters the workspace. The operator can then recover his delay by skipping the $4^{\text {th }}$ vehicle and handles the $5^{\text {th }}$ vehicle.

\section{Mathematical model of the movements of an operator}

An efficient spacing constraint is the one which is capable of smoothing the workload of the operators such that the number of times the utility workers are summoned is minimal, given that the constraint is respected in the car sequence. To model the movements of an operator and hence the solicitation of a utility worker we will use the following notations:

$T_{i, j}$ : The duration of operations on vehicle $j$ at workstation $i$

$D_{i, j}$ : The starting time of operations on vehicle $j$ at workstation $i$

$F_{i, j}$ : The ending time of operations on vehicle $j$ at workstation $i$.

$S_{i, j}$ : A flag which signals the presence of an important delay. $S_{i, j}=1$ if the operator at workstation $i$ requires help for vehicle $j$ and $S_{i, j}=0$ otherwise.

We will also assume that: (i) Operators can treat all vehicles $j$ in their workstation $i$, i.e. $\operatorname{Max}_{i}-\operatorname{Min}_{i} \geq \underset{j}{\operatorname{Max}}\left(T_{i, j}\right)$, (ii) Operators do not face any technical (e.g. breakdown of a screw driver) or logistic problems (e.g. missing parts), (iii) Utility workers are summoned early enough to take in charge the vehicle requiring an intervention, (iv) The pool of utility workers is sufficiently dimensioned to fulfil every alert, (v) The walk-back time of the operator is not explicitly modelled: the return time being rather fast compared to the $T_{c y c l e}$ we considered it as a fixed value and included it in the duration of operations $T_{i, j}$. Such simplifications are commonly used in the literature (see Bard et. al. (1992) for infinite return velocities and Bolat et. al. (1994) for fixed durations added to station times). We note that in the literature, there exist studies which explicitly model the finite return velocities. The interested reader can refer to the work by Klampfl et. al. (2006) which addresses the workstation layout optimization issues in order to minimize the walk-back and waiting time of the operator in a mixed model assembly line context.

\footnotetext{
${ }^{2}$ In certain assembly lines the alarm systems exist to warn the utility worker in time for an upcoming
} 
Based on the above notations and assumptions, the solicitation of a utility worker for a vehicle $j$ at a workstation $i$, is expressed by equation (1).

$$
\begin{aligned}
& D_{i, 1}=0, \forall i \\
& F_{i, j}=D_{i, j}+T_{i, j} \\
& S_{i, j}=\left\{\begin{array}{l}
0 \text { if } F_{i, j} \leq \operatorname{Max}_{i} \\
1 \text { if } F_{i, j}>\operatorname{Max}_{i}
\end{array}\right. \\
& D_{i, j}=\left\{\begin{array}{l}
\operatorname{Max}\left(\operatorname{Min}_{i}, F_{i, j-1}-T_{\text {cycle }}\right) \text { if } S_{i, j-1}=0 \\
\operatorname{Max}\left(\operatorname{Min}_{i}, D_{i, j-1}-T_{\text {cycle }}\right) \\
\text { else }
\end{array}, \quad \forall i, j>1\right.
\end{aligned}
$$

As noted in equation (1), $D_{i, j}$ depends on the initial location of the operator: For the first vehicle of the day, $j=1$, the operator starts at the beginning of his work space : i.e. $D_{i, 1}=0$. For the rest of the vehicles (i.e. $\mathrm{j}>1$ ), the first line in the equation of $D_{i, j}$ refers to the case when the operator can treat the previous vehicle without help (i.e. $S_{i, j-1}=0$ ). In this case, the reference for the ending time of operations on the $(j-1)^{t h}$ vehicle is the $F_{i, j-1}$. Since a new vehicle arrives to the workstation every $T_{c y c l e}$ units of time, $F_{i, j-1}-T_{\text {cycle }}$ gives the point where the operator can catch up the next vehicle in his work space. If $F_{i, j-1}-T_{c y c l e} \leq \operatorname{Min}_{i}$ then the operator has time to walk back up to the extreme boundaries of his workstation before the $j^{\text {th }}$ vehicle arrives to his workstation (i.e. $D_{i, j}=\operatorname{Min}_{i}$ ). If $F_{i, j-1}-T_{c y c l e}>\operatorname{Min}_{i}$ the $j^{\text {th }}$ vehicle has already crossed the practical boundaries of the workstation and the operator can start treating the $j^{\text {th }}$ vehicle from $D_{i, j}=F_{i, j-1}-T_{\text {cycle }}$ on. The second line of the equation for $D_{i, j}$ expresses the fact that the vehicle $(j-1)$ is skipped (i.e. it is taken in charge by the utility worker). In this case the ending time of the operations for $(j-1)^{t h}$ vehicle corresponds to $D_{i, j-1}$ since the regular operator does not treat this vehicle. He can walk upstream to take in charge the $j^{\text {th }}$ vehicle. The logic of calculations is the same as before with $D_{i, j-1}$ taken as the ending time of operations for the previous vehicle.

In this model, only a vehicle having $T_{i, j}>T_{\text {cycle }}$ (i.e. a work intensive vehicle) can induce an emergency alarm. A vehicle having $T_{i, j}<T_{\text {cycle }}$, on the other hand, may be scheduled after a work intensive vehicle to help the operator to recover the accumulated delay. Hence the use of 


\section{A measure of the quality of a car sequence}

We recall that the objective of constraining a car sequence using spacing constraints is to have a smooth workload for the operators and hence to avoid the solicitation of utility workers. When respected in the construction of the car sequence, a good spacing constraint should attain this objective. In order to measure how well the spacing constraints are respected, we use the indicator, $I_{c_{k}}$, given in equation (2) which counts the number of vehicles which do not respect the spacing constraint $k$ (denoted $c_{k}$, here after), (Joly, 2005). This function is very similar to the one proposed by (Fliedner and Boysen, 2008) and provides the same evaluation for a given sequence.

$$
I_{c_{k}}=\sum_{j=1}^{Q_{\text {tot }}}\left(x_{j, k} * \min \left(\max \left(-N_{k}+\sum_{l=j-P_{k}+1}^{j} x_{l, k}, 0\right), 1\right)\right)
$$

$Q_{t o t}$, the number of vehicles in the sequence,

$N_{k} / P_{k}$, the ratio of $c_{k}$,

$x_{j, k}=1$ if the vehicle at position $j$ in the car sequence has the criterion of $c_{k}, 0$ otherwise.

Figure 3 illustrates the calculation of $I_{c_{k}}$ for which the criterion is the "luxury vehicles" and the ratio is $1 / 5$. Given the sequence of vehicles, every sliding window of 5 
vehicles is observed. Each violation of the constraint by a "luxury vehicle" will result in a 1 and no violation will result in 0 . The vehicles which don't respect the ratio are counted once (circled in the figure). For this sequence, the number of violations is 2 , and so $I_{c_{k}}=2$.

\section{[FIGURE 3 HERE]}

The overall quality of a sequence is obtained by aggregating equation 2 for all spacing constraints in a weighted sum as in equation 3 . The weights, $\omega_{k}$, are assigned to each constraint according to its importance, by the line balancing staff and based on experience. Some constraints are related to critical options and have to be met under all circumstances (a high $\omega_{k}$ is assigned) while others can be violated if necessary (a low $\omega_{k}$ is assigned). Here, we will assume that each constraint is equally important and $\omega_{k}=1, \forall k$. A good quality car sequence is the one which has the minimal, $I_{s c}$.

$$
I_{c}=\sum_{k=1}^{N b_{c}} \omega_{k} * I_{c_{k}}
$$

Where $N b_{c}$ is the number of spacing constraints and $\omega_{k}$ is the weight of $c_{k}$

In this article, we will use the indicator given in equation 3 to measure and to compare the quality of car sequences.

\section{Definition of the criteria of spacing constraints}

One conclusion that we can draw from section 2 is that in order to minimize the number of times a utility worker is called up, the work intensive vehicles are to be spaced out. If we are able to characterize these vehicles, this will provide us with the criteria of a spacing constraint. In this section, we will first explain how this characterization can be done. To this end, we will first describe the relationship between a workstation and a spacing constraint.

In the classical car sequencing problem, (see for instance, (Parello et. al,1986), (Yano et al. 1991), (Bolat and Yano, 1992a, 1992b) and (Kim, 2001)), a spacing constraint is defined for a workstation with two kinds of vehicles: either the operator installs an option (e.g. CD player, right hand side wheel, automatic gear, air bags, electrically powered windows, etc.) on the vehicle and this creates a heavy workload, or the operator doesn't install this option on the vehicle and a low workload is observed. We will call this a "one option-two temporization" problem. 
This hypothesis might hold for the early periods of the automobile assembly lines. However, in the current assembly lines, the diversity of vehicles is such that this point of view is no longer valid: An operator may install several different options, variants of an option (e.g. different engine specifications) or the same option with different quantities (eg. airbag only on driver side or on both driver and passenger sides). This results in multiple temporizations in the workstations.

\section{Representation of the workload of an operator}

The assembly tasks performed in a workstation are various and so are the duration of the tasks. In figure 4, all vehicles $j$ to be produced in workstation, $i$, are sorted in ascending order of $T_{i, j}$. The vehicles having the same $T_{i, j}$ are grouped together and represented graphically. Throughout this article, this representation will be used to illustrate the workload of an operator.

\section{[FIGURE 4 HERE]}

In the example workstation illustrated by figure 4, there are 5 different operation times. There are 2 groups of vehicles with $T_{i, j}<T_{\text {cycle }}$ (in light grey) and 3 groups of vehicles with $T_{i, j}>T_{\text {cycle }}$ (in dark grey). The workloads generated by the former groups of vehicles are very low compared to the cycle time (leaving the operator idle) while the latter groups of vehicles generate heavy workloads (and an inevitable delay for the operator).

\section{The relationship between a workstation and the criterion of a spacing constraint}

The challenge is to create a balanced car sequence such that the vehicles with $T_{i, j}>T_{\text {cycle }}$ are distanced from each other by inserting enough vehicles with $T_{i, j}<T_{\text {cycle }}$ in between. As a consequence, we expect that a spacing constraint should be able to represent the vehicles having $T_{i, j}>T_{\text {cycle }}$. In order to quantify the capability of a criterion to represent the work intensive vehicles of workstation $i$, we need to compare two subsets of vehicles assembled in this workstation. Let, $V$ be all the vehicles to be produced on the assembly line.

$$
\begin{aligned}
& V_{C_{k}}=\{v \in V \mid v \text { has the criterion of the spacing constraint } \mathrm{k}\} \\
& V p_{i}=\left\{v \in V \mid T_{i, v}>T_{\text {cycle }}\right\}
\end{aligned}
$$


where $V p_{i} \neq \varnothing$ and $V c_{k} \neq \varnothing$. Indeed, a workstation with $V p_{i}=\varnothing$ can accept any sequence of vehicles without causing delays for the operator. Similarly, if $V c_{k}=\varnothing$, this means that there are no vehicles to space.

Table 1 below summarizes 5 different relationships which exist between a workstation $i$ and a spacing constraint $k$. Depending on these relationships, a spacing constraint will be more or less efficient to handle work overloads generated in a workstation. In the literature, only the first type of relationship is considered (eg. Giard and Jeunet, 2006).

\section{[Table 1. HERE ]}

Each relationship of table 1 is illustrated via figures 5 to 9 . In figures 5 to 9 , the diagram presented in section 3.1 is used to illustrate the workload of an operator in a workstation. For illustration purposes, we present each workstation as a two-temporisation station: vehicles creating no overloads (in light grey) and vehicles source of overloads (in dark grey). Nevertheless, if a more detailed presentation is required, the diagram will look like the one in figure 4 . The cardinality of each set represents the quantity of each type of vehicles. The slim bar under the diagram represents the vehicles characterized by the criterion of a spacing constraint, i.e. $\left(V_{c_{k}}\right)$. In figures 5 to 9 , we consider the same spacing constraint and 5 different workstations. We assume $|V|=1000$ and $\left|V_{c_{k}}\right|=500$.

- In figure 5, $V c_{k}=V p_{i}$ meaning that all vehicles which overload workstation $i$ are exactly those who has the criterion of $c_{k}$. Hence for this workstation, there is a perfect match between the criterion of $c_{k}$ and the vehicles which should be spaced. In this case, we say that « the workstation $i$ is constrained by the spacing constraint $k »$.

\section{[FIGURE 5 HERE]}

- If $V c_{k} \cap V p_{i}=V p_{i}$ and $V c_{k}-V p_{i} \neq \varnothing$ as in figure $6, c_{k}$ not only covers all vehicles which overload workstation $i$ but even more. The 400 vehicles out of 900 which do not overload the workstation are also characterized by the same constraint. The constraint suggests that these 400 vehicles should be spaced in the sequence as well. In other words, $c_{k}$ over-estimates the representation of troublesome vehicles. In this case, we say that «the workstation $i$ is overconstrained by the spacing constraint $k »$. 
[FIGURE 6 HERE]

- Assume that $V p_{i} \cap V c_{k}=V c_{k}$ and $V p_{i}-V c_{k} \neq \varnothing$ as in figure 7. In the figure, only 500 out of 700 work intensive vehicles are covered by $c_{k}$ in the workstation $i$ and the remaining 200 is considered as vehicles which do not need to be spaced. In other words, $c_{k}$ under-estimates the vehicles which overload workstation $i$. In this case, we say that «the workstation $i$ is under-constrained by the spacing constraint $k »$.

\section{[FIGURE 7 HERE]}

- If $V c_{k} \cap V p_{i} \neq \varnothing, V p_{i} \cap V c_{k} \neq V c_{k}$ and $V c_{k} \cap V p_{i} \neq V p_{i}$, as in figure 8, then $c_{k}$ fails to cover a part of the vehicles which overload workstation $i$. Indeed 50 vehicles among 520 with $T_{i, j}>T_{\text {cycle }}$ do not have the criterion of $c_{k}$. Furthermore, it estimates that 30 vehicles which create no peaks in the workstation should be distanced from each other in the car sequence. In other words, $c_{k}$ can handle only a part of the potential problems. In this case, we say that « the workstation $i$ is impacted by the spacing constraint $k »$.

\section{[FIGURE 8 HERE]}

- And finally, if $V c_{k} \cap V p_{i}=\varnothing$ as in figure 9, then $c_{k}$ fails completely to identify the target vehicles for this workstation. In this case, we say that «the workstation $i$ is not impacted by the spacing constraint $k »$.

[FIGURE 9 HERE]

One important conclusion that we draw from the above discussion is that the criterion selected for a spacing constraint will have a different effect on each workstation: for some workstations the criterion selected is a perfect match while for others it has no impact at all. Unfortunately, the solution cannot be defining a criterion for every workstation. In an automotive assembly line, there are several hundreds of workstations. Defining a spacing constraint for each and every workstation is not reasonable since finding a car sequence which satisfies each and every constraint will not be possible. In practice, the number of spacing constraints (hence the number of criteria to define) is much less than the number of workstations. For instance, in the case of the French car manufacturer PSA Peugeot Citroën 
the number of spacing constraints is in the order of 10 . In the rest of the section we propose a method to evaluate the effects of different criteria on different workstations.

\section{Hierarchy of relationships}

The first question is how to rank the relationships among each other. Naturally, a good criterion is the one which characterizes all vehicles with $T_{i, j}>T_{\text {cycle }}$ in workstation $i$. Then, for the extreme cases (i.e. the first and the last relationship) the answer is straightforward. The first relationship (figure 5) is perfect and will be ranked first while the fifth relationship (figure 9) is without interest and hence will be ranked last. The difficulty is with the ranking of the intermediary relationships (figure 10).

\section{[FIGURE 10 HERE]}

In figure 10, for a given workstation, we illustrate 3 different criteria to represent a spacing constraint. If we have to select one of them, which one shall we take?

\section{Three levels of impact factors}

To answer the above question we propose 3 levels of impact factors. The first one estimates the pertinence of the criterion of a spacing constraint with respect to a workstation (in section 3.4.1). This value will then be aggregated over all criteria in order to obtain the impact factor of the set of all spacing constraints on a workstation (see, section 3.4.2) and reaggregated once more with respect to all workstations in order to obtain a measure for the whole assembly line (in section 3.4.3).

\section{The impact factor of a criterion on a workstation}

To evaluate the level of pertinence of the criterion of $c_{k}$ with respect to a workstation $i$, we propose the impact factor, $I_{p_{i, k}}$ (equation 4$)$.

$$
I_{p_{i, k}}=\frac{\operatorname{Card}\left(V c_{k} \cap V p_{i}\right)}{\operatorname{Card}\left(V p_{i}\right)} * \frac{\operatorname{Card}\left(\overline{V c_{k}} \cap \overline{V p_{i}}\right)}{\operatorname{Card}\left(\overline{V p_{i}}\right)}
$$

Where $\overline{V c_{k}}=V-V c_{k}, \overline{V p_{i}}=V-V p_{i}$ and $\operatorname{Card}(Y)$ is the cardinality of the set $Y$

$I_{p_{i, k}}$ varies between 0 and $1 . \ll 0 »$ corresponds to a station not impacted by the spacing constraint and « $1 »$ corresponds to a station constrained by the spacing constraint. In fact, $I_{p_{i, k}}$ is the product of two covering rates: 
(i) $\frac{\operatorname{Card}\left(V c_{k} \cap V p_{i}\right)}{\operatorname{Card}\left(V p_{i}\right)}$ gives the percentage of vehicles with $T_{i, j}>T_{\text {cycle }}$ that are covered by the criterion of $c_{k}$.

(ii) $\frac{\operatorname{Card}\left(\overline{V c_{k}} \cap \overline{V p_{i}}\right)}{\operatorname{Card}\left(\overline{V p_{i}}\right)}$ gives the percentage of vehicles with $T_{i, j}<T_{\text {cycle }}$ that are not covered by the criterion of $c_{k}$.

A workstation not impacted by a spacing constraint has $I_{p_{i, k}}=0$ because $V c_{k} \cap V p_{i}=\varnothing$ $\Leftrightarrow \operatorname{Card}\left(V c_{k} \cap V p_{i}\right)=0$. Whereas a workstation constrained by a spacing constraint has an impact factor equal to 1 because $V c_{k}=V p_{i} \Leftrightarrow V c_{k} \cap V p_{i}=V p_{i}$ et $\overline{V c_{k}} \cap \overline{V p_{i}}=\overline{V p_{i}}$.

For the numerical example of figure 10, the calculation of the 3 criteria gives:

«Impacted »

$$
\rightarrow I_{p_{i, k}}=\frac{\operatorname{Card}\left(V c_{k} \cap V p_{i}\right)}{\operatorname{Card}\left(V p_{i}\right)} * \frac{\operatorname{Card}\left(\overline{V c_{k}} \cap \overline{V p_{i}}\right)}{\operatorname{Card}\left(\overline{V p_{i}}\right)}=\frac{490}{500} * \frac{490}{500}=0,96
$$

«Under-constrained» $\rightarrow I_{p_{i, k}}=\frac{\operatorname{Card}\left(V c_{k} \cap V p_{i}\right)}{\operatorname{Card}\left(V p_{i}\right)} * \frac{\operatorname{Card}\left(\overline{V c_{k}} \cap \overline{V p_{i}}\right)}{\operatorname{Card}\left(\overline{V p_{i}}\right)}=\frac{350}{500} * \frac{500}{500}=0,70$

«Over-constrained» $\rightarrow I_{p_{i, k}}=\frac{\operatorname{Card}\left(V c_{k} \cap V p_{i}\right)}{\operatorname{Card}\left(V p_{i}\right)} * \frac{\operatorname{Card}\left(\overline{V c_{k}} \cap \overline{V p_{i}}\right)}{\operatorname{Card}\left(\overline{V p_{i}}\right)}=\frac{500}{500} * \frac{300}{500}=0,60$

The criterion with the $I_{p_{i, k}}=0,96$ gives the best coverage of the workstation and hence should be chosen. For this example, the intermediary relationships are ordered as impacted $>$ under-constrained $>$ over-constrained. We note that the ranking will completely be different if the data is modified.

\section{The impact factor of the set of criteria on a workstation}

As we have mentioned before, the number of criteria is in the order of 10 for the whole assembly line. For a given workstation each one of them will have a different impact factor value. In order to obtain a global impact factor for a given workstation, we propose the impact factor $I_{p_{i}}$ (equation 5). Indeed, the relationship with the highest impact factor will condition the spacing of the work intensive vehicles in that workstation. 


$$
I_{p_{i}}=\max _{k \in C}\left(I_{p_{i, k}}\right)
$$

Where $C$ is the set of all spacing constraints selected

The impact factor $I_{p_{i}}$ can be used to supervise the assembly line. By ordering the workstations by ascending or descending order of $I_{p_{i}}$, the person in charge of the assembly line balancing can easily identify the workstations which will need a particular supervision. Indeed, the weaker the $I_{p_{i}}$ is for a workstation, the less efficient is a set of spacing constraints to identify the work intensive vehicles at this workstation. Hence, the operator risks accumulating difficulties. The degree of difficulty depends, of course, on the quantity of vehicles with $T_{i, j}>T_{\text {cycle }}$ and $\left|T_{i, j}-T_{\text {cycle }}\right|$ in this workstation.

The impact factor of the set of criteria on the assembly line

To evaluate the global impact of the spacing constraints selected on the overall assembly line, we propose an indicator, $I_{p}$, as an average of the impact factors $I_{p_{i}}$ over all workstations having at least one vehicle with $T_{i, j}>T_{c y c l e}$ (see equation 6). $I_{p}$ can be used to compare different sets of spacing constraints or to evaluate the impact of exchanging a $c_{k}$ with another one.

$$
I_{p}=\frac{\sum_{i \in W_{p w}} I_{p_{i}}}{\left|W_{p w}\right|} \text { where } W_{p w} \text { is the set of workstations with at least } 1 \text { work intensive }
$$

$$
\text { vehicle }
$$

\section{The correlation between $I_{p_{i, k}}$ and solicitation of utility workers}

In this section we will investigate the correlation between $I_{p_{i, k}}$ and the number of times a utility worker is called up. For illustration purposes, we will perform the tests on a single workstation, for a single constraint and for car sequences of 300 vehicles.

The data which concern the workstation is as follows: $T_{\text {cycle }}=2$ minutes. The workstation has two temporisations: $T_{1, j}=1$ minute for all $j$ where $T_{1, j}<T_{\text {cycle }}$ and $T_{1, j}=4$ 
minutes for all $j$ where $T_{2}>T_{\text {cycle }}$. The practical limits are taken as Min $=0$ and Max $=4$. The ratio $\mathrm{N} / \mathrm{P}$ for this constraint is equal to $1 / 3$.

The data related to the vehicles are as follows: Every vehicle has got two attributes: one to indicate if the vehicle is high workload or not, and the other one to indicate if the vehicle has the criterion of the spacing constraint or not. A sequence is generated as follows: Since the spacing constraint is calculated to be $1 / 3$, in the sequence of 300 vehicles, every third vehicle in the sequence is considered to have the criterion. Hence, a sequence generated is optimal in terms of the number of violations of the spacing constraints, i.e. $I_{c}=0$ (see equation 3). Then, the number of work intensive vehicles is chosen randomly between 0 and 100. These vehicles are positioned randomly among the 300 vehicles.

Figure 11 gives the number of times a utility worker is summoned versus the impact factor $I_{p_{i, k}}$, for 10000 randomly chosen production plans for 300 vehicles. For each one of the production plans, the impact factor $I_{p_{i, k}}$ is calculated using equation (4) and 200 car sequences are generated as described above. Then for every car sequence generated, the number of solicitations of utility workers is calculated using equation (1). Each point in figure 11 corresponds to one of the 10000 production plans with his $I_{p_{i, k}}$ on the $\mathrm{x}$-axis and the average number of solicitations of utility workers over the 200 car sequences on the $y$-axis.

\section{[FIGURE 11 HERE]}

As we can observe in this figure, the closer the impact factor to 1 , the lower the number of interventions of utility workers is. In the example of figure 11 , the average coefficient of variation of the number of times the utility workers are called up is 0,019 . This also comforts the observation that the $I_{p_{i, k}}$ can identify significantly well the need for the utility workers. Hence, we conclude that our impact factor $I_{p_{i, k}}$ captures correctly the difficulties of an operator and can be used as a measurement of the quality of the chosen criteria.

\section{Defining a ratio for a spacing constraint}

Definition of a spacing constraint requires the choice of a criterion to represent heavy workload vehicles and the computation of a ratio to space these vehicles in the sequence. In the previous section we presented a method for the choice of the most relevant criteria. In this section we will propose a method to compute the ratio associated to each selected criterion. 


\section{Simplification of the durations of assembly tasks}

In an assembly line with high diversity of vehicles, the workstations will experience diverse $T_{i, j}$ values associated to different tasks performed. Considering each $T_{i, j}$ separately for the calculation of $N / P$ values will tremendously increase the computational complexity. To overcome this computational difficulty, (Giard and Jeunet, 2006), propose a method to simplify the representation of a workstation with great diversity (and consequently, with various duration of work, $T_{i, j}$ ) into a workstation with two temporizations:

(i)A unique duration of assembly tasks, $T_{\text {sup }}$, is assigned to all vehicles with $T_{i, j}>T_{\text {cycle }}$.

(ii)A unique duration of assembly tasks, $T_{\mathrm{inf}}$, is assigned to all vehicles with $T_{i, j}<T_{\text {cycle }}$.

[FIGURE 12 HERE]

Figure 12 illustrates an example of this simplification. In this example, $T_{\text {inf }}$ and $T_{\text {sup }}$ are assigned the highest $T_{i, j}$ values of the vehicles having $T_{i, j}<T_{\text {cycle }}$ and $T_{i, j}>T_{\text {cycle }}$, respectively. This is a worst case scenario. In this article, for the numerical tests, we will consider the worst case scenario as described above as well as an optimistic (i.e. $T_{\text {inf }}$ and $T_{\text {sup }}$ are assigned the lowest $T_{i, j}$ in each group) and an average case scenarios (i.e. $T_{\text {inf }}$ and $T_{\text {sup }}$ are assigned the mean of $T_{i, j}$ values in each group).

To compute the ratio $N / P$, only the temporisations $T_{\text {inf }}$ and $T_{\text {sup }}$ are considered. We note that in reality the workstation will continue to experience 5 different durations of assembly tasks. Next, we will explain how the calculations are carried out, subject to this simplification.

\section{The calculation of a ratio for a given workstation}

In practice, $N$ and $P$ which define the ratio of a spacing constraint are often deduced from the number of vehicles having the criterion and the total number of vehicles to produce, respectively. Duration of the assembly tasks required by this criterion and the additional workload generated by other vehicles are not taken into consideration. However, as we have seen in section 2, the magnitude of a delay generated by a vehicle depends on the duration of the assembly tasks. We have also observed that the delay is compensated more or less rapidly 
depending on the duration of tasks on the vehicles which do not have the criterion. Hence, the calculation of $N$ and $P$ by using only the volume of production is not satisfying.

The approaches adopted in the literature like (Yano and Rachamadugu, 1991), (Bolat and Yano, 1992a, 1992b) or more recently, (Giard and Jeunet, 2006), compute a ratio, N/P, considering the information on the duration of the assembly tasks and the workload of an operator. (Bolat and Yano, 1992a) propose a regenerative sequencing procedure. It is suggested that a maximum number of consecutive vehicles with $T_{i, j}>T_{\text {cycle }}$ which a workstation can accept without requiring a utility worker is scheduled first (i.e. $N$ ). Then a maximum number of vehicles having $T_{i, j}<T_{\text {cycle }}$ are assigned consecutively to recover the delay (i.e. $P-N$ ). Repeating this pattern will regenerate the sequence when the operator becomes idle either because he returns naturally back to his initial position after the treatment of a vehicle or a utility worker is called up at one point of the sequence. In (Bolat and Yano, 1992a), the length of the work station is given in terms of number of jobs. Below we give the notations in terms of temporisations. Nevertheless, the calculation of the ratio $N / P$ remains the same. We note that, each notation is defined for a workstation $i$ and we dropped the index $i$ from the notation for the sake of simplicity.

$T_{\text {sup }}$ and $T_{\text {inf }}:$ as defined in the previous section.

$R_{\max }:$ The maximum delay that an operator can accumulate,

$R_{\text {sup }}$ : Supplementary delay that a vehicle with $T_{i, j}>T_{\text {cycle }}$ adds up to the workload of the operator.

$R_{\text {inf }}$ : Reduction in delay obtained by assigning a vehicle having $T_{i, j}<T_{c y c l e}$ in the car sequence.

$R_{\max }, R_{\text {sup }}$ and $R_{\text {inf }}$ are calculated as in equation (7). $N$ and $P$ are calculated as in equation (8).

$$
\begin{aligned}
& R_{\mathrm{inf}}=T_{\text {cycle }}-T_{\mathrm{inf}}, \\
& R_{\text {sup }}=T_{\text {sup }}-T_{\text {cycle }}, \\
& R_{\text {max }}=(\text { Max }- \text { Min })-T_{\text {cycle }},
\end{aligned}
$$

where Max and Min delimits the workspace of the operator as before. 


$$
N=\left\lfloor\frac{R_{\text {max }}}{R_{\text {sup }}}\right\rfloor \text { and } P=N+\left\lceil\frac{N^{*} R_{\text {sup }}}{R_{\text {inf }}}\right\rceil
$$

In the earlier works, N/P is calculated either for a single workstation (Bolat and Yano, 1992a, $1992 \mathrm{~b}$ ) or it is considered to perfectly cover all workstations in the case of multiple ones (Giard and Jeunet, 2006). Both assumptions are unrealistic in industrial applications. In the next section, we present how to choose $N / P$ which is compatible with the workload of several workstations.

\section{The calculation of the ratio of a spacing constraint}

As we have seen in section 3.4, the criterion of a spacing constraint can constrain several workstations. The ratio $N / P$ found using equation 8 is calculated based on the data of a single workstation. Consequently, for a given criterion which constrains several workstations, we may find different ratios to respect simultaneously. However in practice, a spacing constraint can have one and only one $N / P$ (see (Joly, 2005) for PSA Peugeot Citroën, (Nguyen et al., 2005) for Renault). Furthermore, it is needed that this ratio, whenever it is respected by the car sequence, allows the production of the highest possible number of vehicles on the assembly line. In this section, we will describe a method which generates such a ratio for a given spacing constraint. First, we give some definitions:

Definition 1. A ratio $N^{\prime} / P^{\prime}$ is compatible with a ratio $N / P$ if all possible combinations of $N^{\prime}$ work intensive vehicles in a window of $P^{\prime}$ vehicles respect the ratio $N / P$. Formally, a ratio $N^{\prime} / P^{\prime}$ is compatible with a ratio $N / P$ if the inequality given in equation (9) is respected (Lesert et al., 2006).

$$
\left\lfloor\frac{P}{P^{\prime}}\right\rfloor * N^{\prime}+\min \left(P-P^{\prime}\left\lfloor\frac{P}{P^{\prime}}\right\rfloor, N^{\prime}\right) \leq N
$$

Hence by definition, if $N^{\prime}=N=1$, then $P^{\prime} \geq P$. To illustrate definition 1 , let's take the example of $N^{\prime} / P^{\prime}=1 / 2$. The ratio $1 / 2$ is compatible with the ratio $2 / 4$ because every sequence of vehicles respecting the ratio $1 / 2$, respects the ratio $2 / 4$ as well. On the other hand, the ratio $2 / 4$ is not compatible with the ratio $1 / 2$ because we can construct sequences of vehicles respecting the ratio $2 / 4$ which do not respect the ratio $1 / 2$.

Definition 2. For a given $c_{k}$ with the ratio $N_{k} / P_{k}$ we can define the set of compatible ratios, $R c_{N_{k} / P_{k}}$, using equation (10). This set corresponds to all ratios $N_{k}^{\prime} / P_{k}^{\prime}$ which are 


$$
R c_{N_{k} / P_{k}}=\left\{N_{k}^{\prime} / P_{k}^{\prime} \mid N_{k}^{\prime} *\left\lfloor\frac{P_{k}}{P_{k}^{\prime}}\right\rfloor+\min \left(P_{k}-P_{k}^{\prime} *\left\lfloor\frac{P_{k}}{P_{k}^{\prime}}\right\rfloor, N_{k}^{\prime}\right) \leq N_{k}, \forall\left(N_{k}^{\prime}, P_{k}^{\prime}\right) \in N^{2}, 0<N_{k}^{\prime}<P_{k}^{\prime}\right\}
$$

Let's assume that the criterion of $c_{k}$ constrains several workstations. Using the above definitions, we calculate $N_{k} / P_{k}$ of $c_{k}$ as follows: For each workstation $i$ constrained by $c_{k}$, we calculate the ratio to apply according to equation (8). For every different possible ratio, we build the set of the compatible ratios $R c_{N_{i} / P_{i}}$ (equation 10). Then, we find the set of common compatible ratios, $C c_{k}$, which are common to every workstation (equation 11). Finally, among the ratios in $C c_{k}$ we choose the ratio $N_{k} / P_{k}$ which has the highest value (equation 12) in order to guarantee the production of the highest number of vehicles. Of course, one may choose any other ratio in the set $C c_{k}$, for instance, the ratio which guarantees to produce the quantity required by the production plan.

$$
C c_{k}=\bigcap_{i \in P c_{k}} R c_{N_{i} / P_{i}}
$$

Where, $P c_{k}$ set of all workstations constrained by $c_{k}$.

$$
N_{k} / P_{k}=\max _{x \in C c_{N_{p} / P_{p}}}(x)
$$

Let's illustrate the above procedure by an example. Assume that there are two workstations constrained by the same spacing constraint for which the criterion is given by the presence or not of the option "sunroof". The first workstation can handle a ratio of 1/2 (i.e. one out of two vehicles in the car sequence can have a sunroof) and the second one a ratio of $2 / 5$. Using equation (10), the set of compatible ratios of $1 / 2$ is found as $R c_{1 / 2}=\{1 / 2,1 / 3,1 / 4$, $1 / 5, \ldots\}$. Similarly, the set of the compatible ratios of $2 / 5$ is $R c_{2 / 5}=\{2 / 5,2 / 6,2 / 7, \ldots, 1 / 3,1 / 4$, $1 / 5, \ldots\}$. The set of the common compatible ratios of these stations is $C_{c}=\{1 / 3,1 / 4,1 / 5, \ldots\}$ (equation 11). As we want to produce the highest number of heavy workload vehicles on these two workstations, we select the ratio 1/3 (by equation 12).

\section{Numerical Experiments}

In this section we will present a series of experiments to test the performance of the method presented in the previous sections. To conduct the experiments, we have generated sequencing data in a systematic manner. 
In the assembly line, (i) the number of workstations with overloads is limited to 30. (ii) $T_{\text {cycle }}=1,4$ minutes.

For each workstation, $i$, (i) $\operatorname{Min}_{i}=-0,7, \operatorname{Max}_{i}=2,1$ minutes. (ii) Number of different values that $T_{i, j}$ can take (denoted $N\left(T_{i, j}\right)$ ) is randomly chosen from the interval $[2, \ldots, 5]$, with equal probability for each outcome. Similarly, $N\left(T_{i, j}<T_{\text {cycle }}\right)$ is chosen randomly from the intervals $\left[1, N\left(T_{i, j}\right)-1\right]$ and consequently $N\left(T_{i, j} \geq T_{\text {cycle }}\right)=N\left(T_{i, j}\right)-N\left(T_{i, j}<T_{\text {cycle }}\right)$. (iii) $T_{\text {inf }}=U N I F\left(0, T_{\text {cycle }}\right), T_{\text {sup }}=U N I F\left(T_{\text {cycle }}, 2 \times T_{\text {cycle }}\right)$. (iv) A group of $T_{i, j}$ belonging to $N\left(T_{i, j}<T_{\text {cycle }}\right)$ (respectively, $N\left(T_{i, j} \geq T_{\text {cycle }}\right)$ ) is assigned the value $T_{\text {inf }}$ (resp. $\left.T_{\text {sup }}\right)$ and the rest of the groups of $T_{i, j}$ (if any) are generated as random variables $U N I F\left(0, T_{\text {inf }}\right)$ (resp. $\left.\operatorname{UNIF}\left(T_{\text {cycle }}, T_{\text {sup }}\right)\right)$. Consequently, in this section, we consider a worst-case scenario for the simplification of the multiple temporization workstations into a two-temporization one. (v) Finally, the number of vehicles having each group of $T_{i, j}$ is also defined from a random uniform distribution such that the total number of vehicles does not exceed the quantity required by the production plan.

For the numerical results which will follow, we have assumed a production plan of 600 vehicles. The characteristics of the vehicles as defined above are than randomly assigned on each vehicle in the production plan, such that each vehicle $j$ is defined as a sequence of $T_{i, j}$ values. Note that this can be translated as the presence (respectively, absence) of one or a set of options if $T_{i, j} \geq T_{\text {cycle }}$ (respectively, $T_{i, j}<T_{\text {cycle }}$ ).

\section{Impact of $I_{p}$ on the invocation of utility workers}

In order to observe the impact of $I_{p}$ on the number of times the utility workers are summoned, we have generated 10 instances as summarized above. We assume that the number of workstations is equal to 30. For each instance, a set of constraints (varying between 1 and 30) are chosen following the method described in previous sections. Then a best sequence is generated with the objective of minimizing the number of violations of the selected spacing constrained. To this end, the sequencing tool of Peugeot-Citroen is used (Joly 2005). Then for each sequence, we calculated the number of times the spacing constraints are violated using equation (2) (i.e. no respect in the following figures). The number of times a utility worker is called up is calculated using equation (1) (i.e. 
emergencies). Finally, comparing the set of emergencies and the no-respects, we can identify the number of times there is a violation of the spacing constraint by a vehicle and the emergency signal is sent out for that same vehicle (no-respect + emergencies). The criteria and the ratios of the spacing constraints are then calculated based on the methods given in the previous sections. Figure 13 illustrates an example result of one of the 10 instances. In this figure we observe that, as the impact factor $I_{p}$ approaches 1 , the number of times the utility worker is called up decreases. Furthermore, most of the emergency calls are identified by a violation of the spacing constraints.

\section{[FIGURE 13 HERE]}

The other 9 instances show similar trends which are summarized by figure 14. Figure 14 illustrates the (mean) evolution of the global impact factor $I_{p}$ and the (mean) difference between the number of emergency calls emitted and the emergencies which are actually captured by the violation of a constraint (i.e. absolute difference) in the generated sequence. The bars on the graph give the standard deviation on the absolute difference. We observe that as $I_{p}$ augments, the absolute deviation between the observed and the detected emergencies diminishes. For the instances generated, the mean absolute deviation can drop as low as 6 emergency calls (with a standard deviation of 1.2 ) when $I_{p}=1$. In order to validate this observation, we conducted a second series of tests in the next section, while keeping the $I_{p}$ value equal to 1 for all sequences generated.

\section{[FIGURE 14 HERE]}

\section{Numerical results for fixed $I_{p}=1$}

Unlike figures 13 and 14 where the number of workstations is fixed at 30, the curves in figure 15 are obtained by varying this number between 1 and 30. For each configuration of $n$ workstations, a new data is generated assuming a spacing constraint per workstation. 
Therefore, $I_{p}=1$ for each configuration. In figure 15 , we observe that both curves «emergencies » and «emergencies + no respect $»$ coincide most of the time or are very close to each other, meaning that when the constraints are chosen such that $I_{p}$ is at its maximum, the emergencies which are identified by the violation of a spacing constraint are the actually observed emergency situations.

Ideally, the best sequence is the one for which all three curves coincide (or very close to each other). In figure 15 , this is the case when the number of constraints is low. However, as the number of constraints increases, the number of violations of the spacing constraints increases faster than the number of times the utility workers are called. This is also observed in figure 13.

\section{[FIGURE 15 HERE]}

A natural reason is the fact that it gets more difficult to generate a sequence which satisfies all constraints as the number of constraints is high. Another reason is due to the simplifications made, such as the translation of a multi temporization work station into a two temporization one. We recall that, we have assumed a worst case scenario (i.e. $T_{\text {inf }}$ and $T_{\text {sup }}$ are assigned the highest $T_{i, j}$ values of the vehicles having $T_{i, j}<T_{\text {cycle }}$ and $T_{i, j}>T_{\text {cycle }}$, respectively.). Hence, a vehicle with $T_{i, j} \approx T_{\text {cycle }}$ will be treated the same as another vehicle having $T_{i, j} \gg T_{\text {cycle }}$. Consequently, violating a constraint related to the former vehicle may not necessarily generate an emergency situation on the assembly line, which explains the difference between the emergencies observed and the number of violations of spacing constraints.

\section{Numerical results when the work stations are assumed to be two-temporization}

In order to investigate the above phenomenon observed in figures 13 and 15 , we conducted new numerical experiments similar to the one given in figure 13 with the additional constraint that $N\left(T_{i, j}<T_{\text {cycle }}\right)=N\left(T_{i, j} \geq T_{\text {cycle }}\right)=1$. That is, all workstations are two-temporization ones (see figure 16). We observe that most of the no respects are now associated to an 


\section{[FIGURE 16 HERE]}

All experiments in this section are conducted with randomly generated data. However, in an industrial context, the input data is quite correlated. For instance, a vehicle will never generate an overload in all workstations, because there exist a correlation between the workstations due to the line balancing. Similarly, there are correlations between vehicles and/or the options. Very often, there are promotional offers and hence similar vehicles will be ordered at a given time period. Likewise, some options are mutually exclusive (or inclusive) generating correlations between options. One drawback of using randomly generated data is that the above-mentioned correlations are quite difficult to obtain. In order to measure the real impact of the method, experiments on real industrial data are required.

\section{An industrial case study}

The discussions in this section will be based on real data from the Sevel Nord production plant of Peugeot-Citroën, for the production scenarios of May 2006.

In May 2006, the 194 (out of more than 200) workstations of the Sevel Nord production plant were subject to at least one vehicle with $T_{i, j}>T_{c y c l e}$. For this case study, we first selected 30 workstations among these 194 workstations. These 30 workstations were chosen because we have noticed that their operators often needed help even though the car sequences respected the actual spacing constraints. The production plan of the $23^{\text {rd }}$ May 2006 which consisted of 719 vehicles is taken as an input data. That day, the cycle time was 1.48 minutes, i.e. 1 minute and 29 seconds and the number of spacing constraints were 11.

\section{The data on the workstations}

Table 2 below illustrates the workload of the selected stations. 
[Table 2. HERE]

The first column contains the identification number of the workstation. The columns Min and Max delimit the workspace of the operators and are provided by the line balancing staff. Each workstation is converted into a two-temporization station. $T_{\text {inf }}$ and $T_{\text {sup }}$ are calculated according to an optimistic, an average and a pessimistic scenario as described below and the respective ratios $N / P$ is calculated for each one of these scenarios using equation (8) :

- The optimistic case: we retain only the lowest duration for both kinds of vehicles, $T_{\text {inf }_{i}}=\min _{v \in V p_{i}}\left(T_{i, v}\right), \forall T_{i, v} \leq T_{c y c l e}$ and $T_{\sup _{i}}=\min _{v \in V p_{i}}\left(T_{i, v}\right), \forall T_{i, v}>T_{c y c l e}$.

- The average case: we calculate the average duration for both kinds of vehicles,

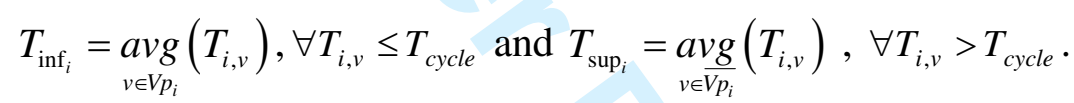

- The pessimistic case: we retain only the highest duration for the both kinds of vehicles, $T_{\text {inf }_{i}}=\max _{v \in V p_{i}}\left(T_{i, v}\right) \forall T_{i, v} \leq T_{c y c l e}$ and $T_{\text {sup }_{i}}=\max _{v \in V p_{i}}\left(T_{i, v}\right), \forall T_{i, v}>T_{c y c l e}$.

\section{The spacing constraints}

In order to illustrate the improvements that can be obtained on the car sequence using our method, we will compare two sets of criteria of spacing constraints: the criteria actually used to generate the car sequence and the criteria proposed by our method. Each set of criteria is used to sequence the vehicles in the production plan of the $23^{\text {rd }}$ of May 2006. In Table 3, on the left hand side, we present the 11 spacing constraints actually used for sequencing the vehicles on the $23^{\text {rd }}$ of May 2006 in the Sevel Nord production site, with the respective ratios used on that day. The matrix on the right hand side represents the impact factor $I_{p_{i, k}}$ calculated for these spacing constraints (on the columns) on each one of the 30 selected workstations (on the rows). The empty cells in the matrix correspond to $I_{p_{i, k}}=0$.

Table 3. HERE 
Table 4. HERE

\begin{abstract}
Next, we define new criteria for 11 new spacing constraints ${ }^{3}$ using our method. For the selection of these criteria, we first assigned a criterion to each one of the 30 workstations. By construction, the criterion of a spacing constraint is defined to identify all work intensive vehicles in that workstation. Since we have 30 workstations, we have initially defined 30 criteria. Then progressively, we removed the criterion which has the least impact on the overall workstations until we obtained 11 criteria to replace the initially defined ones. These criteria are given in a matrix, on the right hand side of table 4.
\end{abstract}

[FIGURE 18 HERE]

The ratio of each spacing constraint is then calculated as described in section 4.3 under an optimistic, an average and a pessimistic scenario (see left hand side of table 4).

Figure 18, illustrates the aggregate impact factors $\left(I_{p_{i}}\right)$ for each workstation with respect to the selected spacing constraints. The global impact factor $I_{p}$ is calculated to be 0.96. Compared to the original set of spacing constraints, our method seems to generate spacing constraints with higher pertinence. To justify our method, we will next compare the quality of sequences generated by the original spacing constraints and the selected ones.

\title{
Comparison of car sequences
}

In order to compare the quality of the car sequences generated using our method and the current one we have performed a series of tests. For each set of spacing constraints (given in tables 3 and 4), we constructed a car sequence using the sequencing tool of PSA Peugeot Citroën. This tool generates sequences with minimum number of violations of the spacing 
constraints (Joly et. al., 2008). Then, using equation (2) we calculated the number of times the spacing constraints are violated (given by the column no respect in table 5). The number of times a utility worker is called up is calculated using equation (1) (i.e. the column labelled emergencies in table 5). Finally, comparing the set of emergencies and the no-respects, we can identify the number of times there is a violation of the spacing constraint by a vehicle and the emergency signal is sent out for that same vehicle (no-respect + emergencies in table 5).

The table 5 summarizes the results. The upper table gives the results for the currently used spacing constraints and the lower table gives the performance under the method proposed in this article. In each table, the first line is a counter of the no respect of spacing constraints, emergencies and (emergencies + no respects) for the workstations under study. The second line is a counter of the same parameters in terms of the number of vehicles. For instance, in the case of the current spacing constraints actually used on the $23^{\text {rd }}$ of May, there were 176 emergency solicitations sent out and these emergencies were related to 100 vehicles (meaning that some vehicles required interventions in more than 1 workstation). And finally in the third line we give the number of workstations with at least one emergency. For instance, in the case of the current spacing constraints, all the emergencies are generated by 11 workstations out of 30 .

Table 5. HERE

Table 5 confirms the general trend which was observed in figures 13 and 14 . The column which summarizes the results for the current spacing constraints adopted by the Sevel Nord production plant shows that even though we may obtain an optimal car sequence with respect to a set of spacing constraints (i.e. no respect $=0$ in table 5) this sequence does not guarantee that no utility workers will be summoned. More importantly, the current spacing constraints were unable to identify the vehicles which will cause a difficulty for the operators: there have been 176 emergencies sent out to call up a utility worker, however none of them was identified as a difficulty via the violation of a spacing constraint (emergencies + no respect $=0$ ). Hence, we can conclude that even though the scheduling tool gives an optimum sequence, the current spacing constraints used for sequencing the vehicles were inefficient to represent the real difficulties encountered on the assembly line.

\footnotetext{
${ }^{3}$ We propose 11 spacing constraints to keep the same number of spacing constraints as in reality (Table 3 ).
} 
On the other hand, when we make the same analysis on our selection of 11 spacing constraints we observe that they tend to be more representative of the real assembly line situation. We remark that obtaining an optimal car sequence (with 0 violations) becomes more difficult which may also be seen as a sign of inadequate line balancing. On the operational point of view, the "emergencies" column is more important than the "no respect" column since the objective is to have a production with the least incidence possible. We note that, with our selection of 11 constraints the number of emergencies has decreased for all three scenarios studied. And the most important of all, the vehicles which generate emergency situations coincide with the vehicles which violate the spacing constraints in the sequence (emergencies + no respect column). Hence, we know for which vehicles an operator might potentially need help as soon as we generate the sequence. As a consequence, the intervention of utility workers can be scheduled in advance, where and when needed.

Further analysis of table 5 has shown that, the more pessimistic we are, the higher the number of no respects is (46 in optimistic scenario vs. 195 in pessimistic one). This is rather expected since the $T_{\text {sup }}$ and $T_{\text {inf }}$ for the pessimistic case are calculated considering the worst case scenarios. Nevertheless, we reduce the number of interventions of utility workers (from 113 to 66 ) if we use the pessimistic scenario. Similarly, the intervention of the utility workers is managed better in the pessimistic case than the other ones. For instance, in the optimistic case, only 26 vehicles were covered by the spacing constraints out of the 99 which created interventions. For the pessimistic case, this number is 62 out of 64 vehicles. ${ }^{4}$

In the pessimistic case, the emergencies without violations of the spacing constraints are exceptional; however the number of violations without any emergencies is very high. In order to understand better these two situations we had a closer look into two workstations which were the major sources of violation of the spacing constraints (see table 6). Indeed, the stations 6 and 13 registered 113 violations out of a total of 195 for the pessimistic case as announced in table 5. For the workstation number 6 , zero emergencies without violations are observed. On the other hand for the workstation number 13 we observe many violations of the spacing constraints but no utility workers were actually needed (i.e. no emergency calls are sent out). The explanation is provided by figure 19. We observe that the assembly tasks in the workstation number 6 are limited to 3 different durations with a unique task requiring an

\footnotetext{
4 This gap of 2 vehicles is explained by the presence of a vehicle for which the duration of the assembly tasks exceeds $\operatorname{Max}_{i}$ for two workstations. This vehicle is placed at the beginning of the sequence. It respects the spacing constraint but generates an emergency call.
} 
operation time greater than the cycle time, meaning that the actual situation of the workstation is already very close to the simplification that we have made when we aggregated every workstation as a two-temporisation workstation. On the other hand, the workstation number 13 handles more diverse assembly tasks with 7 different durations which vary from 0.07 to 1.92 minutes. Hence the simplification of this workstation by a two-temporisation station does not give a good approximation of the real situation. The conclusion that can be drawn from this analysis is that if the line balancing is done such that the different temporisations on a workstation are closer to each other (for the vehicles having $T_{i, j} \leq T_{\text {cycle }}$ and for those having $T_{i, j}>T_{\text {cycle }}$ ), then the selected criteria will be more pertinent in representing the real difficulties of the assembly line.

Table 6. HERE

\section{[FIGURE 19 HERE]}

\section{Sensitivity analysis on the number of constraints}

The analysis in the previous section is performed for the case of 11 spacing constraints in order to have a common basis of comparison with the current situation at PSA. We recall that only 11 constraints were defined at the company for the period under study. Figure 20 below shows a comparative study on the number of constraints. The objective is to observe the impact of the number of constraint on the quality of the solutions obtained. This analysis is based on the initially chosen 30 workstations and hence will be limited to 30 constraints. We make 3 major observations from figure 20: (i) $I_{p}$ is greater than 0,98 for a number of spacing constraints $\geq 12$. Hence, based on our method we expect to obtain a good coverage of the 30 workstations using 12 constraints (ii) for a number of constraints $\geq 12$, the number of emergencies which are identified by violation of spacing constraints (i.e. emergencies + no respect) coincides with the number of emergencies sent out. Augmenting the number of spacing constraints above 12 does not improve the early detection of emergencies (we even observe degradation in the number of emergencies for more than 16 spacing constraints). (iii) As we increase the number of constraints above 12, the difficulty of constructing a car sequence increases as well (i.e. no-respects increases). However, the number of emergencies 


\section{Analysis considering all workstations}

In the previous sections, the experiments were conducted on the initially chosen 30 workstations. In this section, we present the results considering the whole assembly line (see figure 21). The spacing constraints are the same as the previously defined ones. We make the following observations based on figure 21. (i) The number of emergencies has naturally augmented since now we are calculating all emergencies occurring in the 194 workstations. (ii) As before, the number of emergencies which are pre-identified by the no-respects (emergencies + no-respects) of the sequence approaches to the number of emergencies. However, we cannot predict each of the emergencies (emergencies and emergencies + norespects do not completely coincide). This is explained by the existence of several workstations which are poorly dimensioned and not sufficiently covered by the selected constraints. (iii) For 15 spacing constraints $I_{p}=0,98$. Hence, we estimate that 15 spacing constraints can correctly cover the whole assembly line. Above 15 constraints, we observe that the performance of the assembly line is stable. Furthermore, augmenting number of constraints above 19 ( $\left.I_{p}=0,998\right)$, will result in car sequences where some of the violations do not correspond to a real emergency on the assembly line.

\section{[FIGURE 21 HERE]}

\section{Conclusion and perspectives}

In this article, we proposed a method which helps defining different elements of a spacing constraint: the criterion and the ratio. Our method contributes to the car sequencing literature since the definition of a spacing constraint has not been handled until now. We have shown that to have a good quality car sequence, it is not sufficient to have high performance scheduling tools which guarantee that no spacing constraints are violated. As long as the spacing constraints are poorly defined, the generated car sequence fails to capture the real 
emergency situations that may arise on the production site. In this sense, we believe that this research work underlines and fills in a fundamental issue in car sequencing problem.

At last, but not the least, our method is also a contribution for the practitioners since we propose new tools for the operations manager to define efficiently the spacing constraints to respect or to evaluate the performance of the existing ones. These tools are currently implemented and used with success at the PSA Peugeot Citroën. The first industrial impact is a smoother planning of the utility workers. Since the occurrences of emergencies can be estimated more accurately, a more precise planning of utility workers can be done. This in turn, has a positive impact on the quality of work done as well as a more efficient utilisation of the pool of utility workers.

Nevertheless, the method can be refined on several points: (i)For the calculation of $N / P$, the multiple temporization workstations are approximated by a two temporization workstation under optimistic, pessimistic and average scenarios. This approach is similar to the one-option-two-temporization hypothesis considered in earlier works (Giard and Jeunet, 2006), (Yano and Rachamadugu, 1991), (Bolat and Yano, 1992a), (Bolat and Yano, 1992b). The scenarios considered in this study can further be refined by calculating statistically significant $T_{\text {inf }}$ and $T_{\text {sup }}$ to guarantee the coverage of the temporization with a certain confidence interval. (ii)For the calculation of the impact factors, we do not take into account the operation times. For instance, for a group of vehicles with $T_{i, j}>>T_{c y c l e}$ a workstation may be much more under-constrained than for another group having $T_{i, j}>T_{c y c l e}$ even though $I_{p_{i, k}}$ may be identical for both cases. Currently, these situations are handled using the pessimistic scenario and considering a very high global $I_{p}$. Nevertheless, the method can be refined either by defining rules which take into account the operation times in case of identical impact factors or by a modification of $I_{p_{i, k}}$ to take into account the operation times.

As another perspective, we may cite the link between the scheduling and the load balancing problems. In the classical approach, the load balancing and the sequencing are performed as successive stages (Thomopoulos, 1967). Our method shows that the load balancing and the sequencing influence each other: The load balancing will influence the criteria and the ratio of spacing constraints which are used in car sequencing. The car sequence, in turn, will affect the real time work load of the workstations. An iterative procedure of line balancing and scheduling may improve the overall performance of the assembly line. 


\section{References}

Baratou, P., 1998. «Gestion réactive de stocks intermédiaires d'un flux de production automobile », Doctoral thesis, Université des Sciences et Technologies de Lille.

Bard, J.F., Dar-El, E. , Shtub A., 1992. "An analytic framework for sequencing mixed model assembly lines" International Journal of Production Research, vol. 30, p. 35-48.

Becker C., Scholl, A, 2006. «A survey on problems and methods in generalized assembly line balancing », European Journal of Operational Research, vol. 168, no. 3, p. 694-715.

Bernier V. and Frein Y., 2004. "Local Scheduling Problems Submitted to Global FIFO Processing Constraints", Int. Jour. of Production Research, Vol. 42, nº, pp. 1483-1503.

Bolat, A., Savsar, M., Al-Fawzan, M. A., 1994. "Algorithms for the real time scheduling of jobs on mixed model assembly lines" Computers and Operations Research, vol. 21, p. 487-498.

Bolat, A., Yano, C., 1992a, "Scheduling algorithms to minimize utility work at a single station on a paced assembly line" Production planning and control, vol. 3, p. 393-405.

Bolat, A., Yano, C., 1992b, "A surrogate objective for utility work in paced assembly lines", Production planning and Control, vol. 3, p. 406-412.

Boysen N., Fliedner M and Scholl A., 2009. «Sequencing mixed model assembly lines: Survey, classification and model critique", European Journal of Operational Research, 192, p. 349-373.

Comby G., 1996, «Aide au séquencement des produits sur une ligne de fabrication multi modèles ». Doctoral thesis, Institut National des Sciences Appliquées de Lyon, 19/12/1996.

El Hadj Khalaf, R., 2006. "Problème du séquencement des véhicules : ajout d'un nouveau critère », Master's thesis, Management Stratégique et Génie des Organisation, Institut National Polytechnique, Grenoble, 30/06/2006.

Fliedner, M., and Boysen, N. 2008. "Solving the car sequencing problem via branch and bound", European Journal of Operational Research, 191, p. 1023-1042.

Giard V., Jeunet J., 2006. «Modélisation du problème général d'ordonnancement de véhicules sur un ligne de production et d'assemblage », Journal Européen des Systèmes Automatisés, vol. 40, no. 4-5, p. 463496.

Joly, A. 2005. «Etude de modes de fonctionnement réactifs et robustes aux aléas sur le flux de production d'une usine terminale automobile», Doctoral thesis, Institut National Polytechnique de Grenoble, 21/03/2005. 
Joly A., Frein Y., 2008. "Heuristics for an industrial car sequencing problem considering paint and assembly shop objectives", Computers \& Industrial Engineering, 55, pp.295-310, 2008.

Kim, Y-M, 2001. « A Quick Sequencing Algorithm for a Mixed Model Assembly Line with Multiple Stations », Korean Journal, p300-303.

Klampfl, E., Gusikhin O., Rossi G., "Optimization of Workcell layouts in a mixed-model assembly line environment," International Journal of Flexible Manufacturing Systems, Volume 17, pp. 277-299, Oct. 2006,

Lesert A., 2006. «Sur l'évaluation de la flexibilité au montage dans une usine terminale automobile », Doctoral thesis, Institut National Polytechnique de Grenoble, 18/12/2006.

Lesert A., Alpan G., Frein Y., Noiré S., 2006. «Outil d'aide à l'analyse des interactions de contraintes pour l'ordonnancement d'une ligne de montage », $6^{\text {ème }}$ Conférence Francophone de MOdélisation et SIMulation, MOSIM'06, 3-5 Avril 2006, Rabat (Maroc).

Lesert A., Alpan G., Frein Y., Noiré S., 2007. «Sur le choix des contraintes d'espacement pour l'ordonnancement des véhicules dans une usine terminale », $7^{\text {ème }}$ Congrès International de Génie Industriel, CIGI'07, 5-8 Juin 2007, Trois-Rivières (Canada).

Nguyen, A., Cung V-D, 2005. «Le problème du Car Sequencing RENAULT et le challenge ROADEF’2005», Proceedings of JFPC.

Parello B., Kabat WC, Wos L, 1986. «Job-Shop Scheduling using Automated Reasoning : a case of study of the Car-Sequencing Problem », Journal of Automated Reasoning, n². p.1-42.

Scholl, A, Becker C., 2006. «State-of-the-art exact and heuristic solution procedures for simple assembly line balancing », European Journal of Operational Research 168, p666-693.

Solnon C., Cung V-D., Nguyen A. and Artigues A, 2007. "The car sequencing problem: overview of state-ofthe-art methods and industrial case-study of the ROADEF'2005 challenge problem », European Journal of Operational Research, available on line since May 2007, DOI:10.1016/j-ejor.2007.04.033.

Thomopoulos, N., 1967. «Line balancing-sequencing for mixed-model assembly », Management Science, Vol $\mathrm{n}^{\circ} 14, \mathrm{n}^{\circ} 2, \mathrm{p} 59-75$.

Tsai, L., 1992. «Mixed-model sequencing to minimize utility work and the risk of conveyor stoppage », Management Science, vol n41, p485-495.

Warwick, Terry, and Tsang, Edward, 1995. «Tackling Car Sequencing Problems Using a Generic Genetic ALgorithm », Evolutionary Computation, Vol n³, p 267-298

Yano, C.A., Rachamadugu, R., 1991. «Sequencing to minimize work overload in assembly lines with product options », Management science, $\mathrm{Vol} \mathrm{n}^{\circ} 37, \mathrm{n}^{\circ} 5$, p572-586. 


\section{LIST OF FIGURE CAPTIONS}

Figure 1. A typical workstation in an automotive assembly line.

Figure 2. Movements of an operator in his workstation

Figure 3. Example of calculation of $I_{s c_{k}}$

Figure 4. Representation of the workload of an operator at his workstation

Figure 5. Station constrained by a spacing constraint

Figure 6. Workstation over-constrained by a spacing constraint

Figure 6. Workstation over-constrained by a spacing constraint

Figure 7. Workstation under-constrained by a spacing constraint

Figure 8 . Workstation impacted by a spacing constraint

Figure 9. Workstation not impacted by a spacing constraint

Figure 10. Example of possible nuances in the relation

Figure 11. The correlation between $I_{p_{i, k}}$ and the number of solicitations of polyvalent operators

Figure 12. Example of simplification of the processing times of a station

Figure 13: Results for instance no. 9

Figure 14. Evolution of $I_{p}$ and the mean absolute difference between the observed and detected emergencies.

Figure 15. Evolution of the emergency calls for $I_{p}=1$

Figure 16. Numerical experiments for two-temporization work stations

Figure 17. Efficiency of the spacing constraints applied on the $23^{\text {rd }}$ May 2006 in Sevel Nord

Figure 18. Efficiency of the selected constraints, for the production plan of $23^{\text {rd }}$ May.

Figure 19. Duration of tasks in stations 6 and 13.

Figure 20. Sensitivity analysis on the number of constraints.

Figure 21. Analysis for the whole assembly line 


\section{FIGURES}

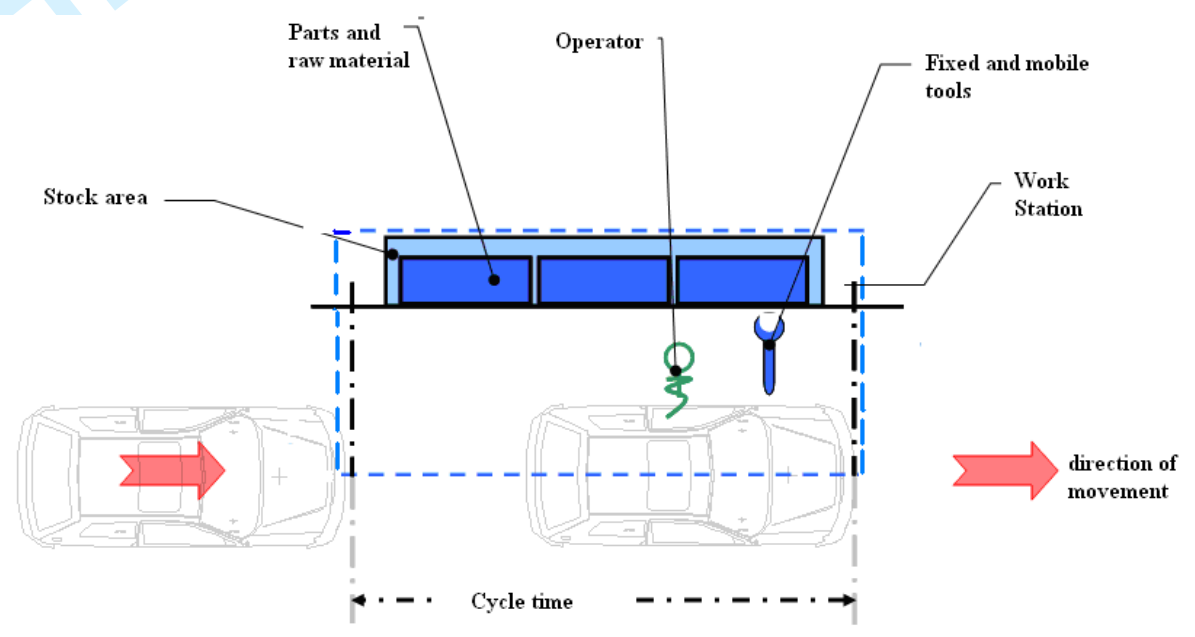

Figure 1. A typical workstation in an automotive assembly line 


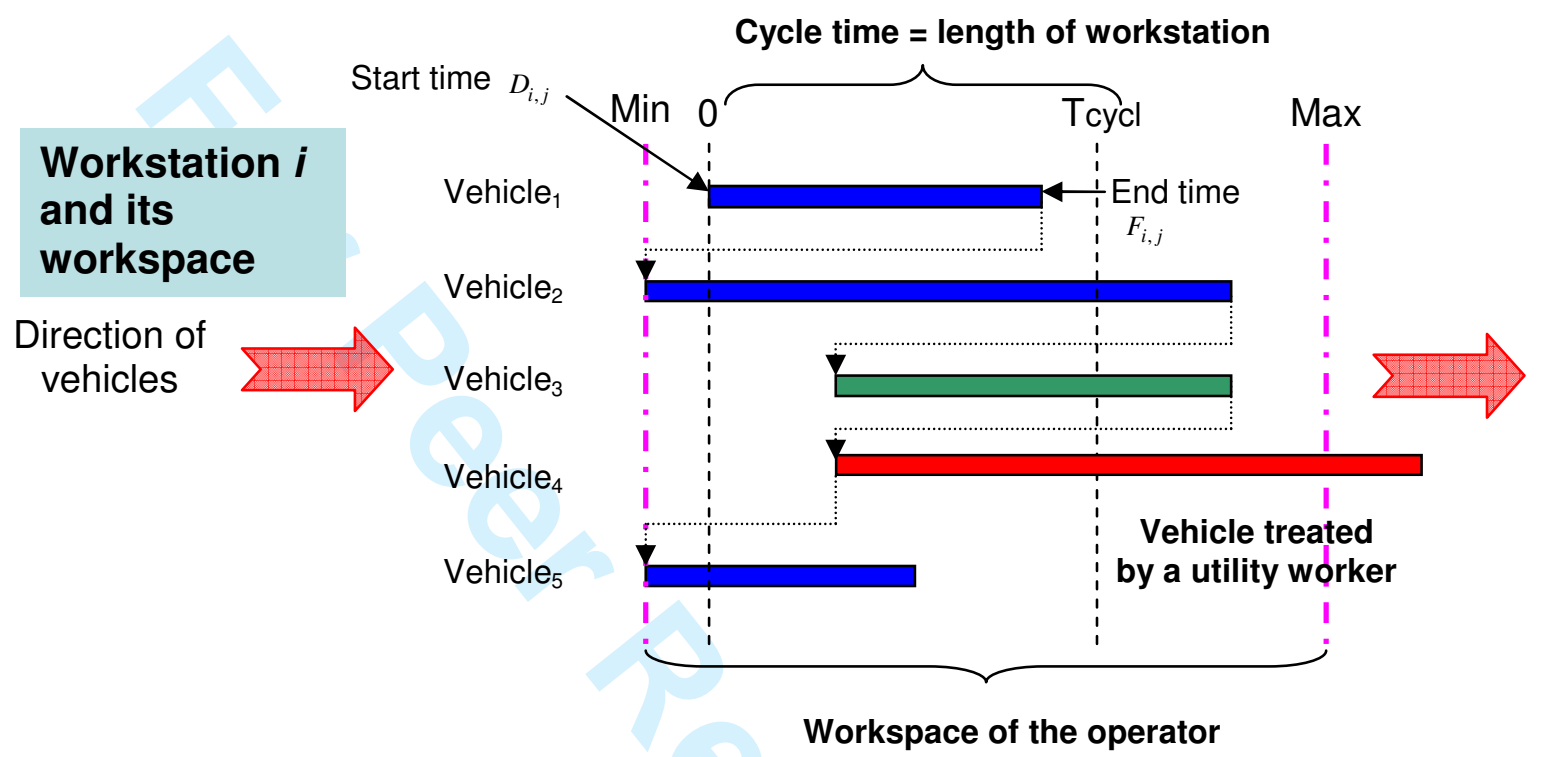

Figure 2. Movements of an operator in his workspace 
1

2

3

4

5

6

7

8

9

10

11

12

13

14

15

16

17

18

19

20

21

22

23

24

25

26

27

28

29

30

31

32

33

34

35

36

37

38

39

40

41

42

43

44

45

46

47

48

49

50

51

52

53

54

55

56

57

58

59

60

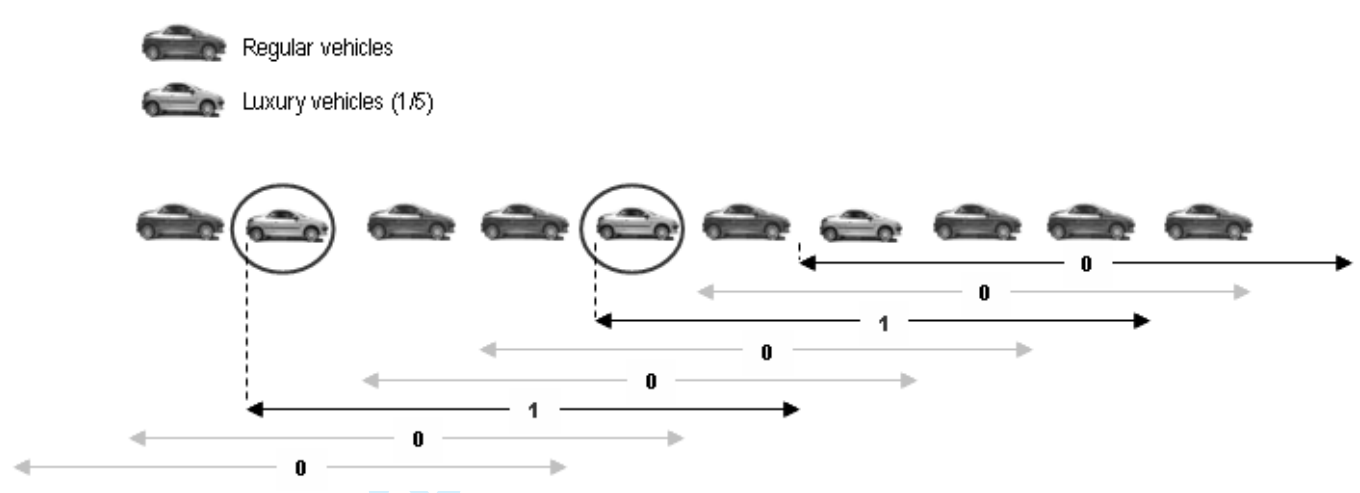

Figure 3. Example of calculation of $I_{c_{k}}$

http://mc.manuscriptcentral.com/tprs Email: ijpr@lboro.ac.uk 
1

2

3

4

5

6

7

8

9

10

11

12

13

14

15

16

17

18

19

20

21

22

23

24

25

26

27

28

29

30

31

32

33

34

35

36

37

38

39

40

41

42

43

44

45

46

47

48

49

50

51

52

53

54

55

56

57

58

59

60

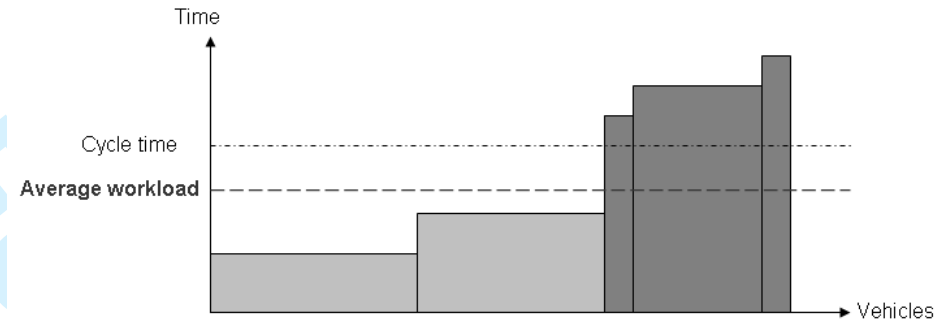

Figure 4. Representation of the workload of an operator at his workstation 


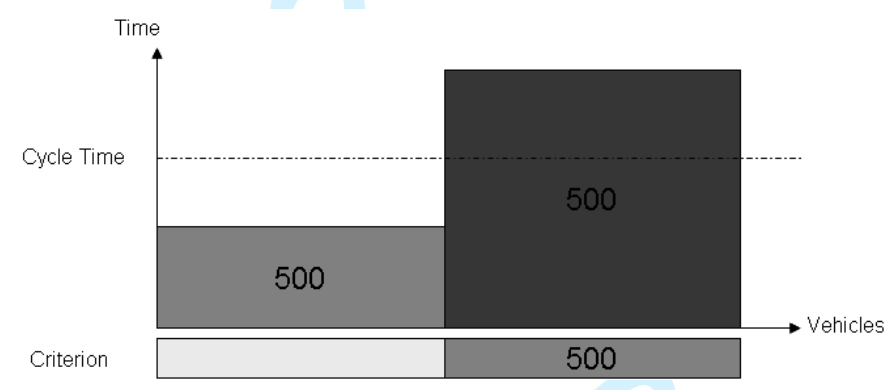

Figure 5. Station constrained by a spacing constraint 
1

2

3

4

5

6

7

8

9

10

11

12

13
14

15

16

17

18

19

20

21

22

23

24

25

26

27

28

29

30

31

32

33

34

35

36

37

38

39

40

41

42

43

44

45

46

47

48

49

50

51

52

53

54

55

56

57

58

59

60

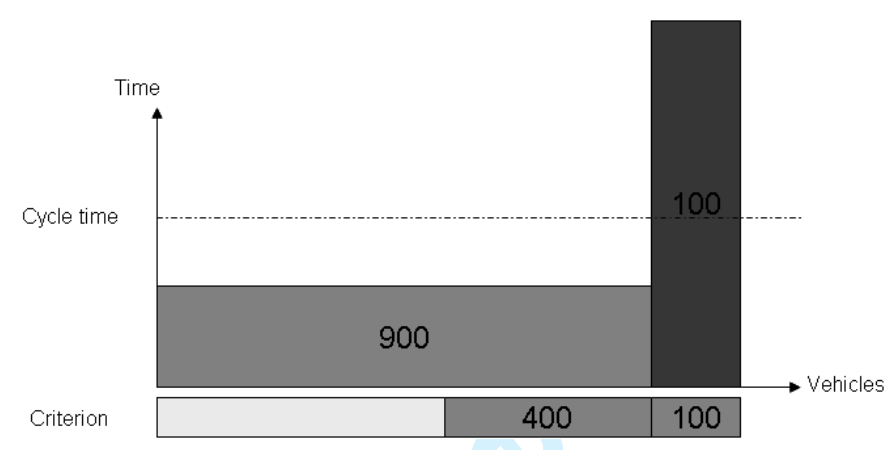

Figure 6. Workstation over-constrained by a spacing constraint 


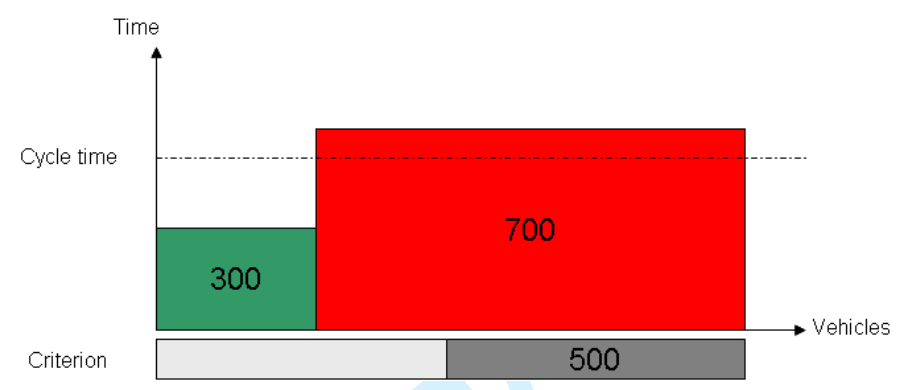

Figure 7. Workstation under-constrained by a spacing constraint 
1

2

3

4

5

6

7

8

9

10

11

12

13

14

15

16

17

18

19

20

21

22

23

24

25

26

27

28

29

30

31

32

33

34

35

36

37

38

39

40

41

42

43

44

45

46

47

48

49

50

51

52

53

54

55

56

57

58

59

60

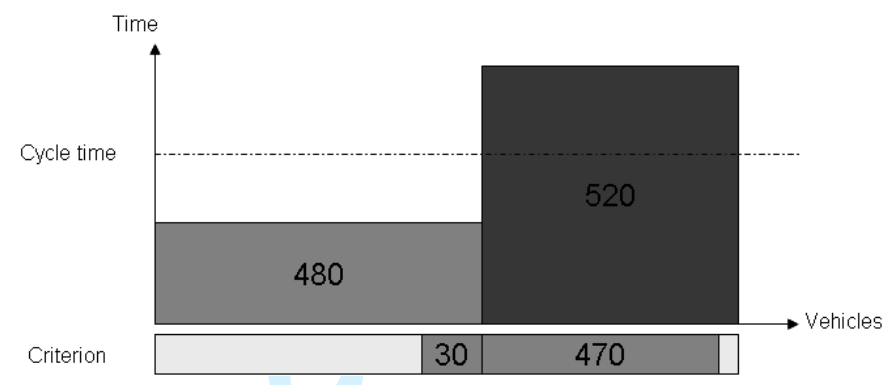

Figure 8 . Workstation impacted by a spacing constraint 

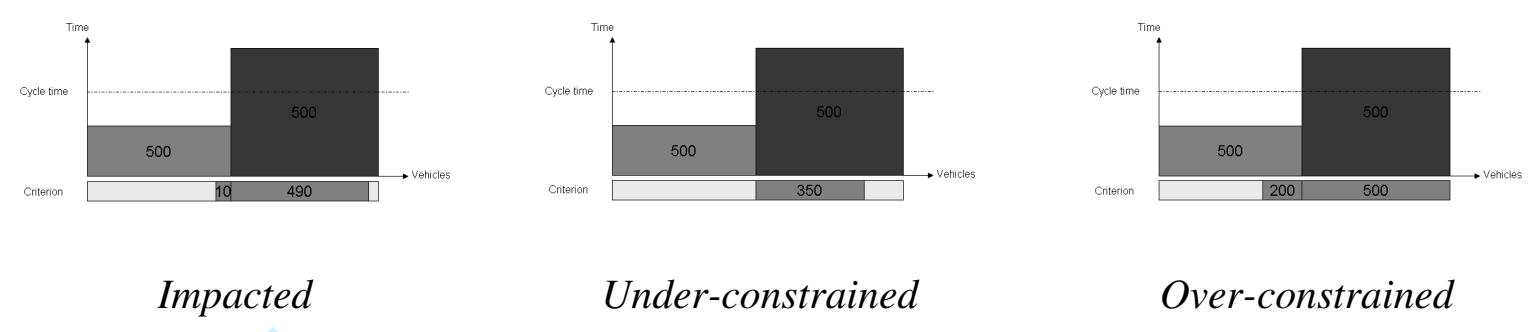

Figure 10. Example of possible nuances in the relation 


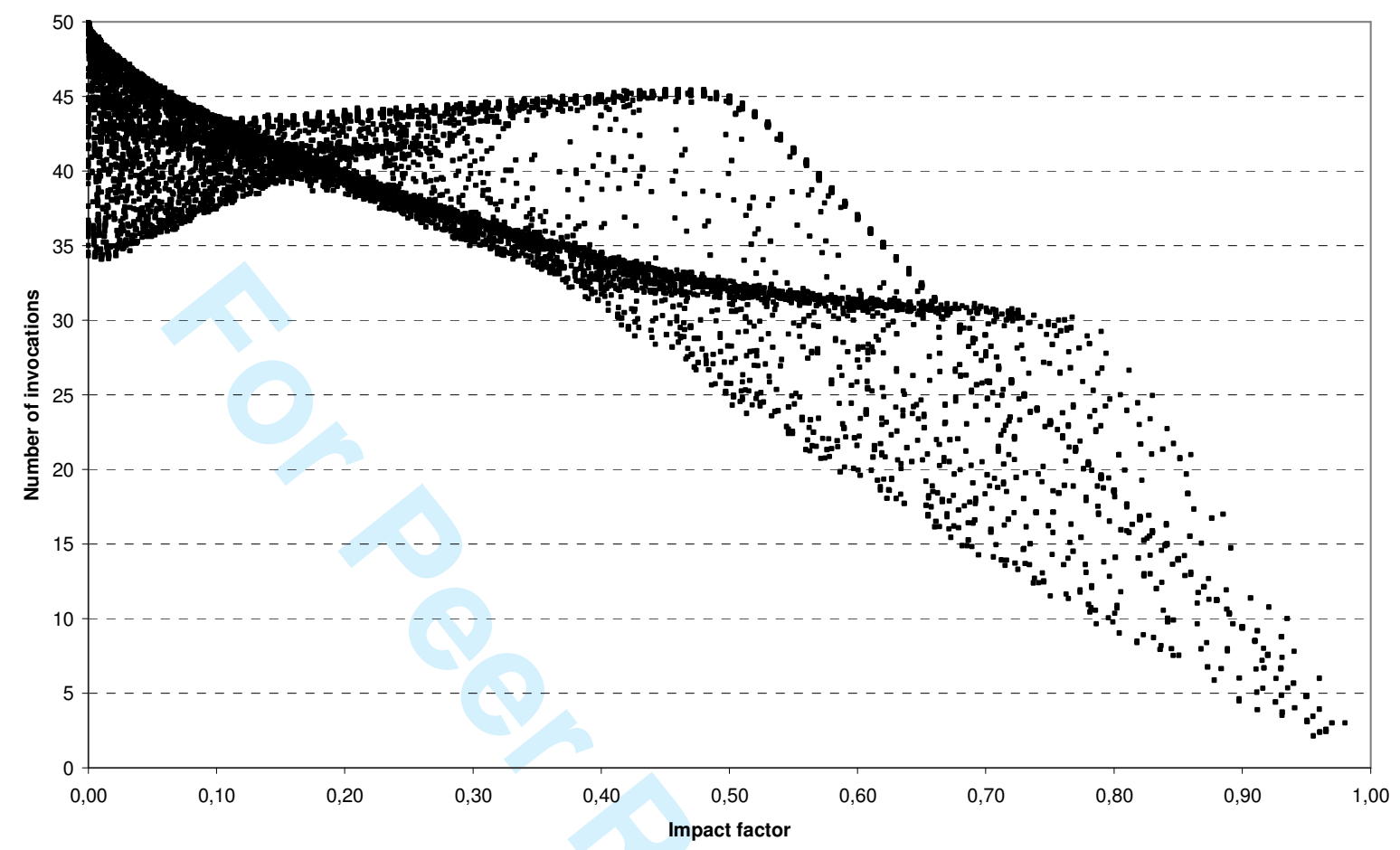

Figure 11. The correlation between impact factor $I_{p_{i, k}}$ and the number of solicitations of utility workers 


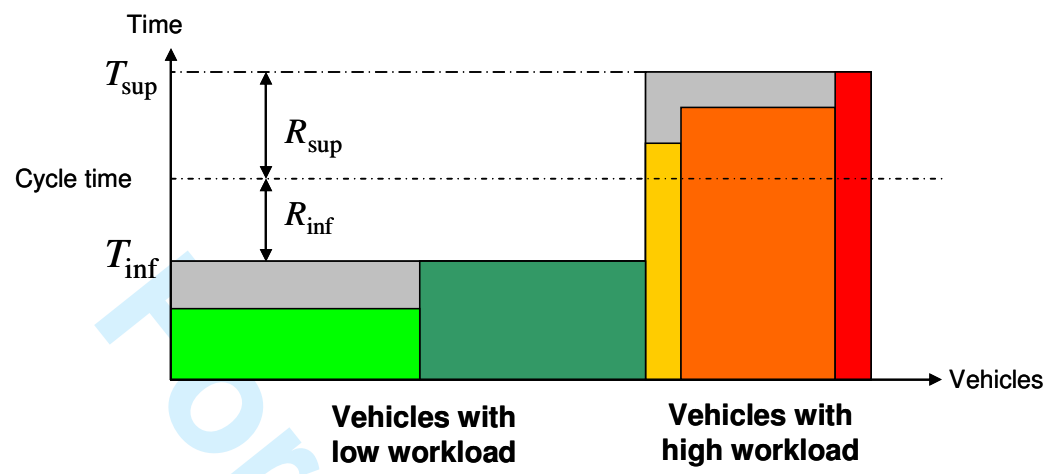

Figure 12. Example of simplification of the processing times of a station 


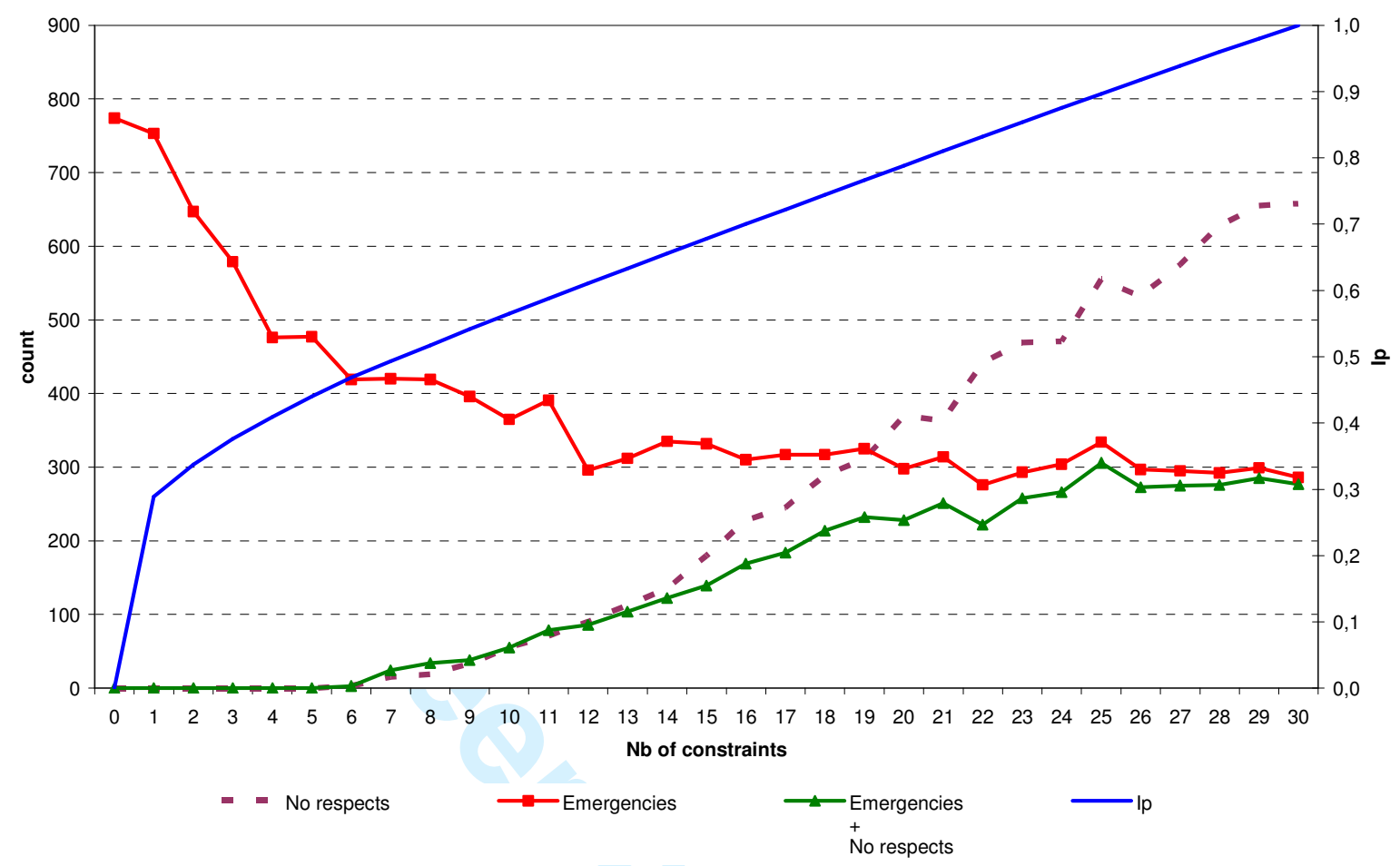

Figure 13: Results for instance no. 9

http://mc.manuscriptcentral.com/tprs Email: ijpr@lboro.ac.uk 


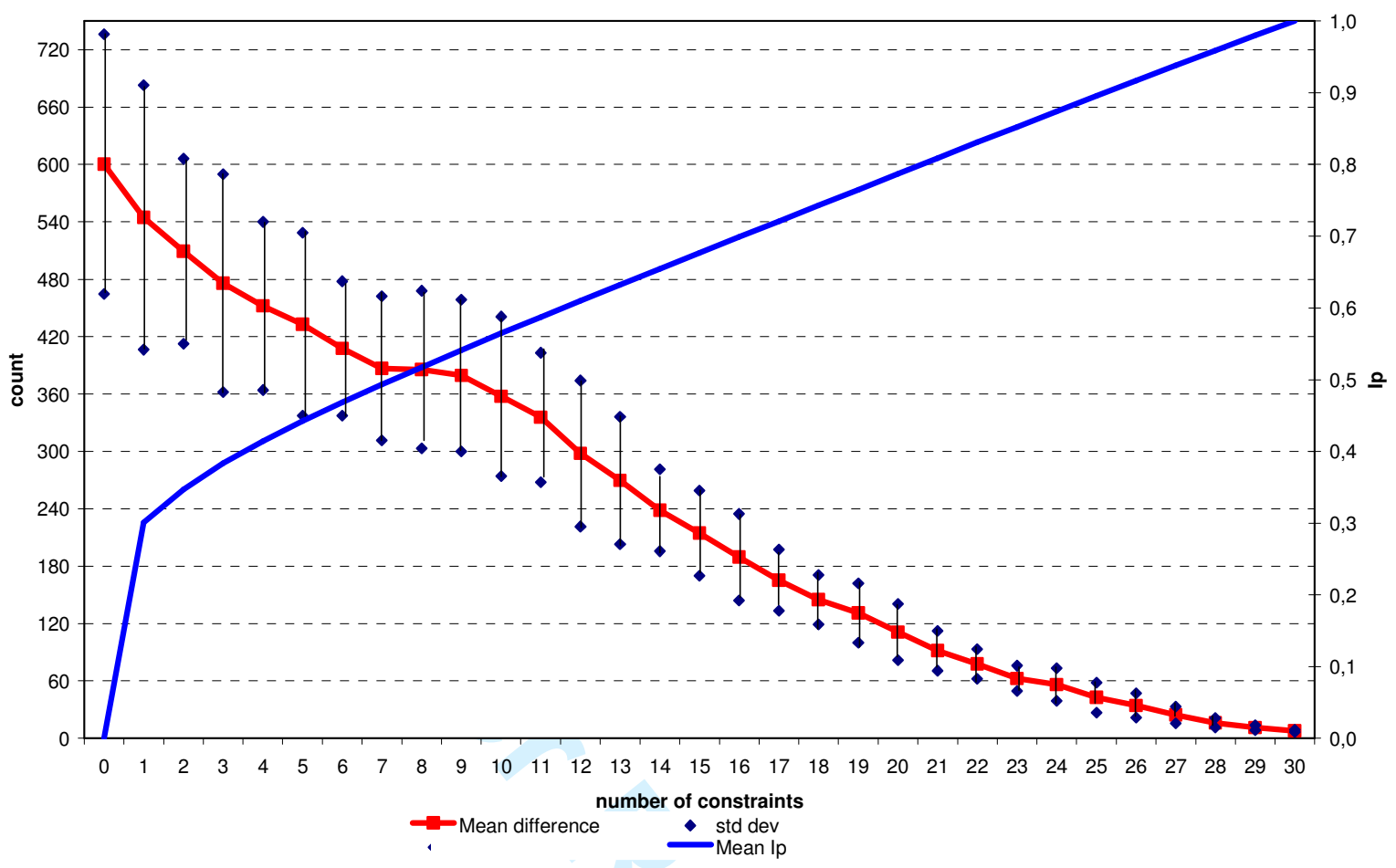

Figure 14. Evolution of $I_{p}$ and the mean absolute difference between the observed and detected emergencies. 


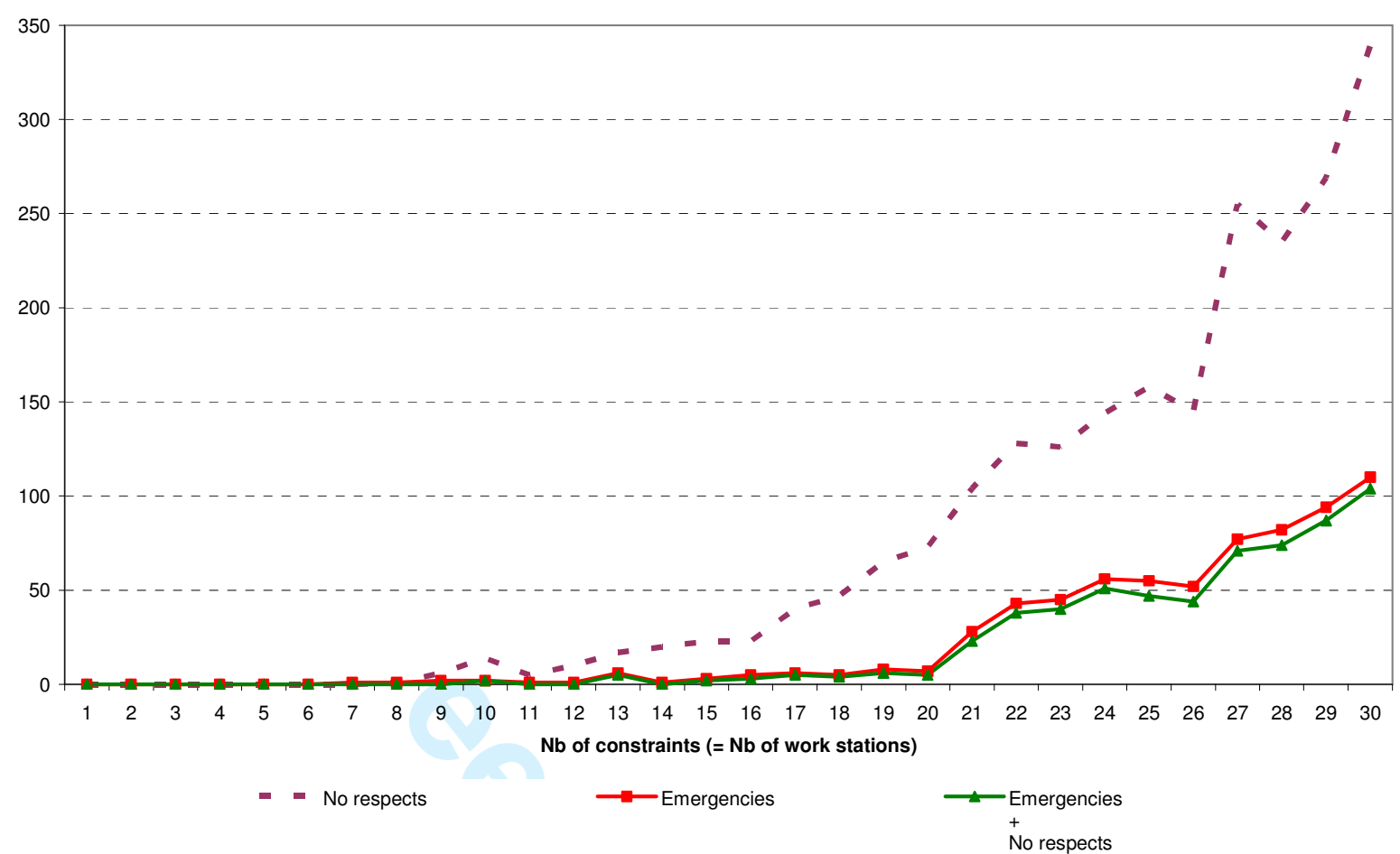

Figure 15. Evolution of the emergency calls for $I_{p}=1$ 


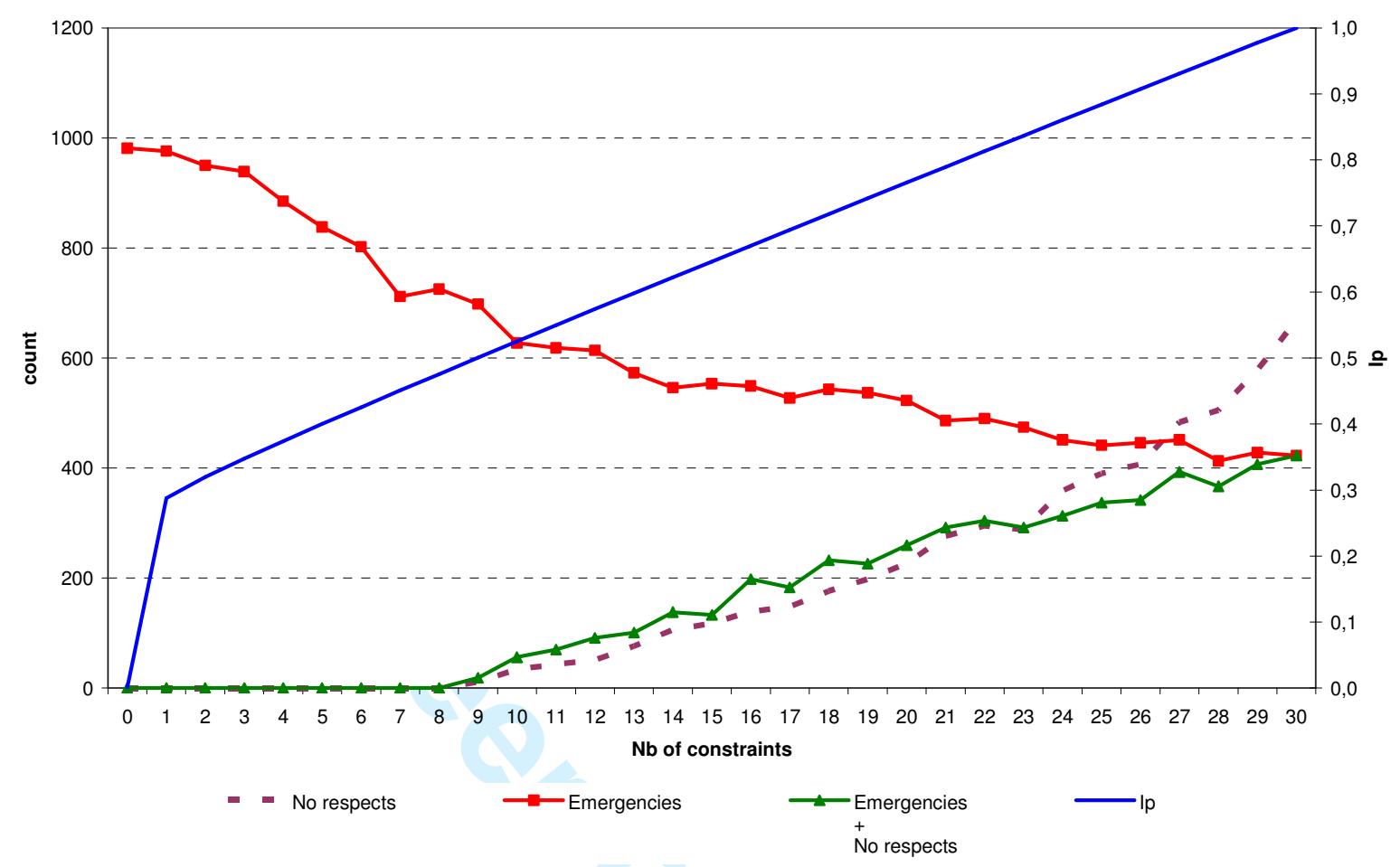

Figure 16. Numerical experiments for two-temporization work stations 


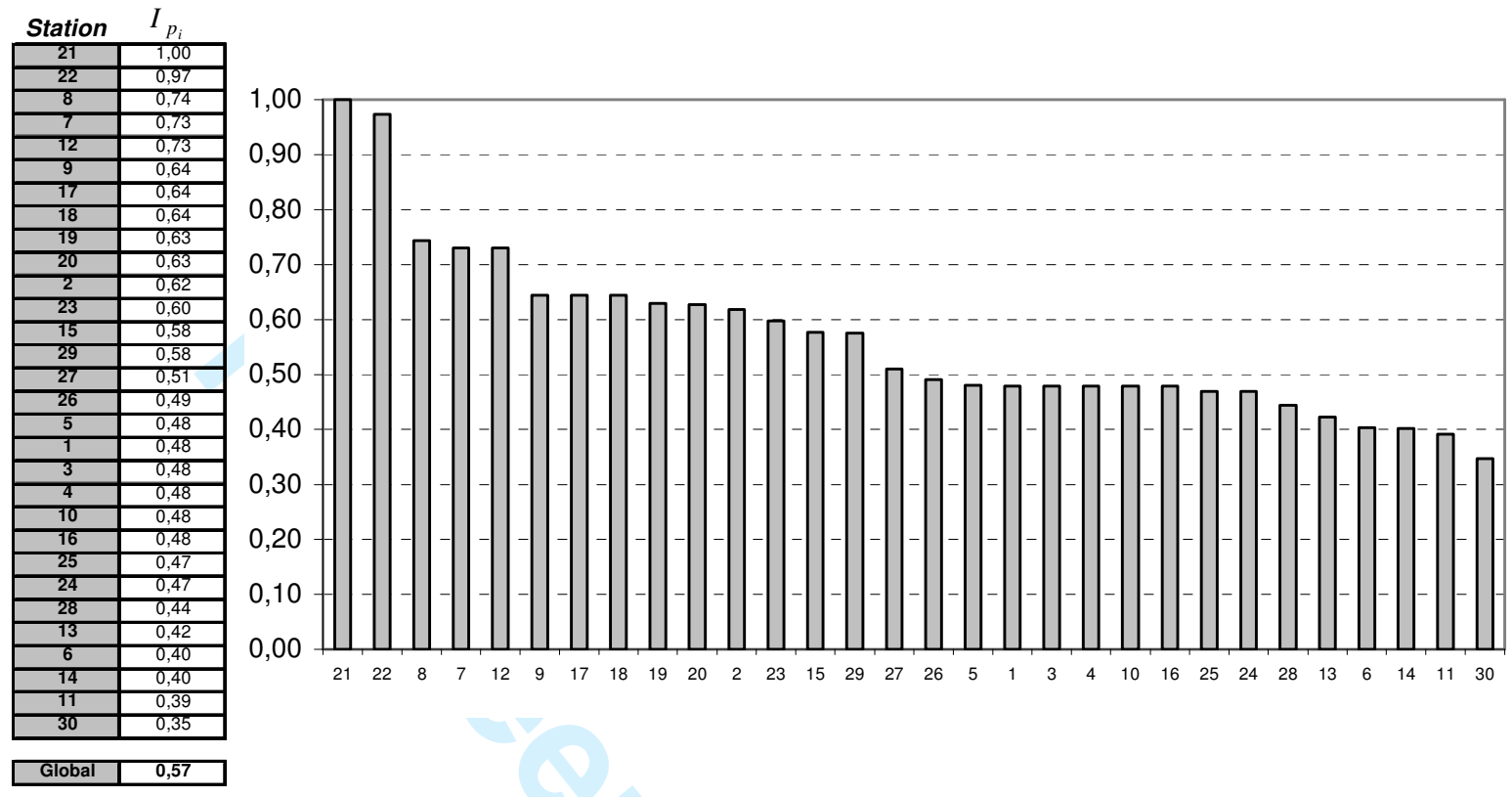

Figure 17. Efficiency of the spacing constraints applied on the $23^{\text {rd }}$ May 2006 in Sevel Nord 

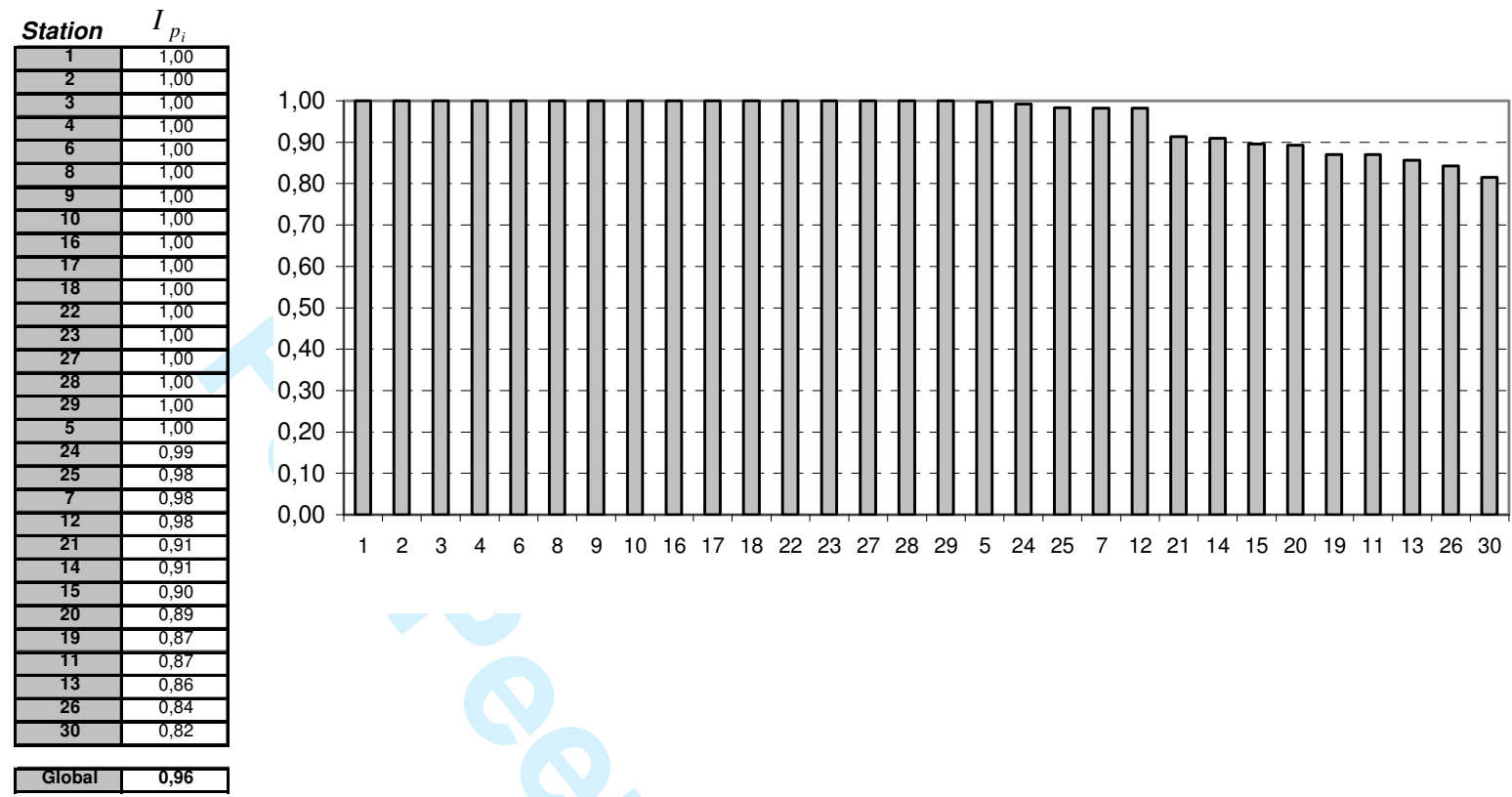

Figure 18. Efficiency of the selected constraints, for the production plan of $23^{\text {rd }}$ May. 


\begin{tabular}{|c|c|}
\hline Time & Number of vehicles \\
\hline 0,07 & 5 \\
\hline 1,04 & 39 \\
\hline 1,09 & 471 \\
\hline $\mathbf{1 , 5 2}$ & $\mathbf{1 2 1}$ \\
\hline $\mathbf{1 , 5 3}$ & $\mathbf{7}$ \\
\hline $\mathbf{1 , 6 9}$ & $\mathbf{2}$ \\
\hline $\mathbf{1 , 9 1}$ & $\mathbf{7 4}$ \\
\hline
\end{tabular}

\begin{tabular}{|c|c|}
\hline Time & Number of vehicles \\
\hline 1,07 & 82 \\
\hline 1,22 & 298 \\
\hline $\mathbf{1 , 5 2}$ & $\mathbf{3 3 9}$ \\
\hline
\end{tabular}

Station 13

Station 6

Figure 19. Duration of tasks in stations 6 and 13 
Figure 20. Sensitivity analysis on the number of constraints. 


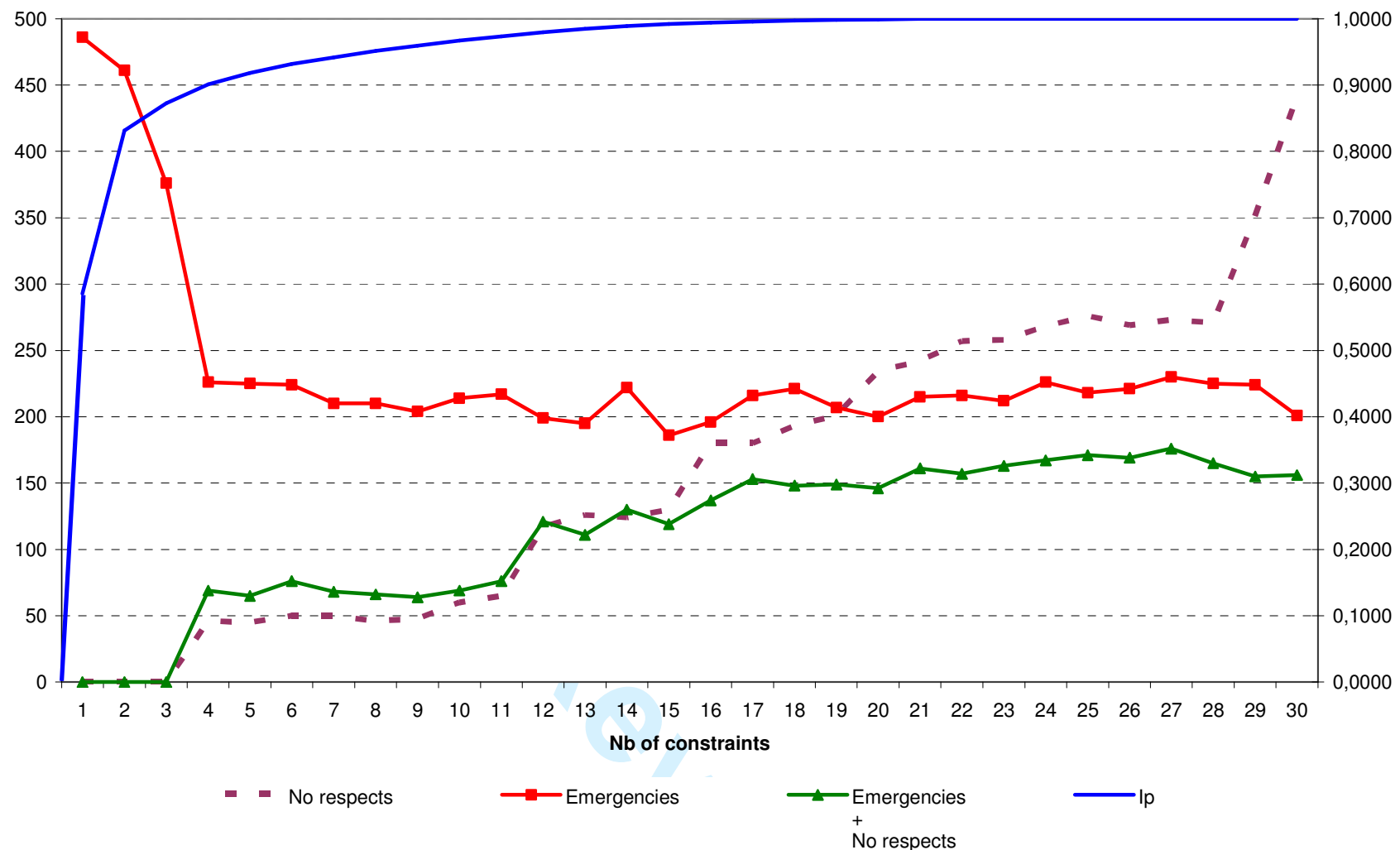

Figure 21. Analysis for the whole assembly line 
Table 1. Relationship between a workstation and a spacing constraint (SC)

\begin{tabular}{|c|c|}
\hline \multicolumn{1}{|c|}{ Condition } & Relationship \\
\hline$V c_{k}=V p_{i}$ & Workstation is constrained by a SC \\
\hline$V c_{k} \cap V p_{i}=V p_{i}$ and $V c_{k}-V p_{i} \neq \varnothing$ & Workstation is over-constrained by a SC \\
\hline$V p_{i} \cap V c_{k}=V c_{k}$ and $V p_{i}-V c_{k} \neq \varnothing$ & Workstation is under-constrained by a SC \\
\hline$V c_{k} \cap V p_{i} \neq \varnothing, V p_{i} \cap V c_{k} \neq V c_{k}$ and $V c_{k} \cap V p_{i} \neq V p_{i}$ & Workstation is impacted by a SC \\
\hline$V c_{k} \cap V p_{i}=\varnothing$ & \\
\hline
\end{tabular}


Table 2. Data related to 30 workstations

\begin{tabular}{|c|c|c|c|c|c|c|c|c|c|c|c|}
\hline & & & & timistic & & & rage Cas & & & simistic & \\
\hline Station & Min & Max & Tinf & Tsup & N/P & Tinf & Tsup & N/P & Tinf & Tsup & N/P \\
\hline 1 & $-0,7400$ & 2,2200 & 0,6400 & 1,7400 & $5 / 7$ & 1,0326 & 1,9875 & $2 / 5$ & 1,0600 & 2,0500 & $2 / 5$ \\
\hline 2 & $-0,7400$ & 2,2200 & 0,6180 & 1,6190 & $10 / 12$ & 0,7493 & 1,6509 & $8 / 10$ & 1,1790 & 1,6990 & $6 / 11$ \\
\hline 3 & $-0,7400$ & 2,2200 & 0,8600 & 2,1800 & $2 / 5$ & 0,8791 & 2,1800 & $2 / 5$ & 0,8800 & 2,1800 & $2 / 5$ \\
\hline 4 & $-0,7400$ & 2,2200 & 0,2800 & 1,6480 & $8 / 10$ & 0,8856 & 1,8987 & $3 / 6$ & 1,1190 & 1,9370 & $3 / 7$ \\
\hline 5 & $-0,7400$ & 2,2200 & 0,4830 & 1,4920 & $123 / 125$ & 1,2099 & 1,6283 & $9 / 14$ & 1,2830 & 1,6820 & $7 / 15$ \\
\hline 6 & 0,0000 & 1,5300 & 1,0700 & 1,5200 & $1 / 2$ & 1,1876 & 1,5200 & $1 / 2$ & 1,2200 & 1,5200 & $1 / 2$ \\
\hline 7 & $-0,7400$ & 2,2200 & 0,7000 & 1,4900 & $148 / 150$ & 0,8096 & 1,6505 & $8 / 11$ & 0,8100 & 1,6900 & $7 / 10$ \\
\hline 8 & $-0,7400$ & 2,2200 & 0,6550 & 1,5280 & $30 / 32$ & 0,7871 & 1,7022 & $6 / 8$ & 0,7900 & 1,7380 & $5 / 7$ \\
\hline 9 & $-0,7400$ & 2,2200 & 0,0000 & 1,6300 & $9 / 10$ & 0,5406 & 2,0520 & $2 / 4$ & 0,6000 & 2,2700 & $1 / 2$ \\
\hline 10 & $-0,7400$ & 2,2200 & 0,2200 & 1,7400 & $5 / 7$ & 0,6993 & 1,8888 & $3 / 5$ & 1,0300 & 1,9500 & $3 / 7$ \\
\hline 11 & $-0,7400$ & 2,2200 & 0,0000 & 1,6600 & $8 / 9$ & 0,6693 & 2,2188 & $2 / 4$ & 0,6900 & 2,3000 & $1 / 3$ \\
\hline 12 & $-0,7400$ & 2,2200 & 0,6920 & 1,6260 & $10 / 12$ & 0,8550 & 1,6494 & $8 / 11$ & 0,9170 & 1,6660 & $7 / 10$ \\
\hline 13 & 0,0000 & 2,2200 & 0,0700 & 1,5200 & $18 / 19$ & 1,0763 & 1,6634 & $4 / 6$ & 1,0900 & 1,9100 & $1 / 3$ \\
\hline 14 & $-0,7400$ & 2,2200 & 0,5500 & 1,7200 & $6 / 8$ & 0,7852 & 2,0832 & $2 / 4$ & 0,8300 & 2,1500 & $2 / 5$ \\
\hline 15 & $-0,7400$ & 2,2200 & 0,6400 & 1,7100 & $6 / 8$ & 0,6400 & 1,7680 & $5 / 7$ & 0,6400 & 1,7900 & $4 / 6$ \\
\hline 16 & $-0,7400$ & 2,2200 & 0,1800 & 2,4300 & $1 / 2$ & 0,1800 & 2,7388 & $1 / 2$ & 0,1800 & 2,7400 & $1 / 2$ \\
\hline 17 & 0,0000 & 3,1300 & 0,0000 & 1,6400 & $10 / 12$ & 0,0000 & 2,7153 & $1 / 2$ & 0,0000 & 2,9400 & $1 / 2$ \\
\hline 18 & $-0,7400$ & 2,2200 & 0,0900 & 1,5000 & $74 / 76$ & 0,0900 & 2,0582 & $2 / 3$ & 0,0900 & 2,1800 & $2 / 4$ \\
\hline 19 & $-0,7400$ & 2,2200 & 0,3400 & 1,5000 & $74 / 76$ & 0,3690 & 1,7336 & $5 / 7$ & 0,3700 & 1,8300 & $4 / 6$ \\
\hline 20 & $-0,7400$ & 2,2200 & 0,4300 & 1,5000 & $74 / 76$ & 0,4300 & 1,7573 & $5 / 7$ & 0,4300 & 1,8500 & $4 / 6$ \\
\hline 21 & $-0,7400$ & 2,2200 & 1,1500 & 1,6700 & $7 / 12$ & 1,2775 & 1,6924 & $6 / 13$ & 1,3800 & 1,7000 & $6 / 20$ \\
\hline 22 & $-0,7400$ & 2,2200 & 1,1760 & 1,7210 & $6 / 11$ & 1,3471 & 1,7210 & $6 / 17$ & 1,4110 & 1,7210 & $6 / 27$ \\
\hline 23 & $-0,7400$ & 2,2200 & 1,1450 & 1,5180 & $38 / 43$ & 1,1461 & 1,6976 & $6 / 10$ & 1,1480 & 1,8090 & $4 / 8$ \\
\hline 24 & $-0,7400$ & 2,2200 & 0,7890 & 1,6270 & $10 / 13$ & 1,0160 & 1,8110 & $4 / 7$ & 1,0590 & 2,0670 & $2 / 5$ \\
\hline 25 & $-0,7400$ & 2,2200 & 0,2700 & 1,7500 & $5 / 7$ & 0,3558 & 1,9428 & $3 / 5$ & 0,4800 & 2,1000 & $2 / 4$ \\
\hline 26 & $-0,7400$ & 2,5200 & 0,6300 & 1,4900 & 178/181 & 0,9753 & 1,6738 & $9 / 13$ & 1,1600 & 1,8000 & $5 / 10$ \\
\hline 27 & $-0,7400$ & 2,2200 & 0,6200 & 1,4900 & $148 / 150$ & 0,9292 & 1,7018 & $6 / 9$ & 1,1450 & 1,7800 & $4 / 8$ \\
\hline 28 & $-0,7400$ & 2,2200 & 1,0930 & 1,4870 & 211/215 & 1,0930 & 1,5255 & $32 / 36$ & 1,0930 & 1,5570 & $19 / 23$ \\
\hline 29 & 0,0000 & 3,2570 & 0,8900 & 1,6300 & $11 / 14$ & 1,3042 & 1,6300 & $11 / 21$ & 1,4600 & 1,6300 & $11 / 94$ \\
\hline 30 & $-0,7400$ & 2,2200 & 1,3500 & 1,5100 & $49 / 61$ & 1,3922 & 1,5297 & $29 / 46$ & 1,4600 & 1,5300 & $29 / 102$ \\
\hline
\end{tabular}




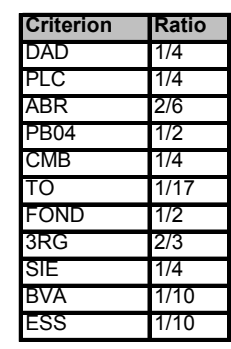

Table 3. Spacing constraints applied the $23^{\text {rd }}$ May 2006 in Sevel Nord

\begin{tabular}{|c|c|c|c|c|c|c|c|c|c|c|c|}
\hline & DAD & PLC & ABR & PB04 & CMB & TO & FOND & 3RG & SIE & BVA & ESS \\
\hline 1 & & & & & & & & 0,48 & 0,15 & & \\
\hline 2 & & & 0,37 & 0,36 & 0,20 & & 0,62 & & & & \\
\hline 3 & & & & & & & & 0,48 & 0,15 & & \\
\hline 4 & & & & & & & & 0,48 & 0,15 & & \\
\hline 5 & & & & & & & & 0,48 & 0,15 & & \\
\hline 6 & 0,13 & 0,17 & & & & & & 0,40 & 0,12 & & \\
\hline 7 & & 0,18 & 0,39 & 0,43 & 0,22 & & & & & & \\
\hline 8 & & 0,18 & 0,40 & 0,41 & 0,20 & & & & & & \\
\hline 9 & & & & 0,13 & 0,17 & & & 0,64 & & & \\
\hline 10 & & & & & & & & 0,48 & 0,15 & & \\
\hline 11 & & & & & & & & 0,39 & 0,19 & & \\
\hline 12 & & 0,18 & 0,39 & 0,43 & 0,22 & & 0,73 & & & & \\
\hline 13 & & & & & & & & 0,42 & 0,21 & & \\
\hline 14 & & & & & & & & 0,40 & 0,18 & & \\
\hline 15 & & & & 0,21 & 0,24 & & & 0,58 & & & \\
\hline 16 & & & & & & & & 0,48 & 0,15 & & \\
\hline 17 & & & & 0,13 & 0,17 & & & 0,64 & & & \\
\hline 18 & & & & 0,13 & 0,17 & & & 0,64 & & & \\
\hline 19 & & & 0,40 & 0,41 & 0,23 & & 0,63 & & & & \\
\hline 20 & & & 0,40 & 0,41 & 0,23 & & 0,63 & & & & \\
\hline 21 & & 0,16 & 1,00 & 0,40 & 0,31 & & 0,35 & 0,14 & & & \\
\hline 22 & & 0,16 & 0,97 & 0,40 & 0,34 & & 0,33 & 0,15 & & & \\
\hline 23 & & & 0,60 & 0,22 & 0,18 & & 0,17 & 0,30 & & & \\
\hline 24 & & & & & & & & 0,47 & 0,15 & & \\
\hline 25 & & & & & & & & 0,47 & 0,15 & & \\
\hline 26 & & & & & & & & 0,49 & 0,14 & & \\
\hline 27 & & & 0,44 & 0,41 & 0,23 & & 0,51 & & & & \\
\hline 28 & & & 0,15 & 0,19 & 0,18 & & & 0,44 & & & \\
\hline 29 & & & 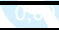 & & & & & 0,42 & 0,58 & & \\
\hline 30 & & & & & & & & 0,35 & 0,20 & & \\
\hline
\end{tabular}

28 
Table 4. Selected spacing constraints and their impact factors

\begin{tabular}{|c|c|c|c|}
\hline Constraint & \multicolumn{3}{|c|}{ Optimistic } \\
Average & Pessimistic \\
\hline 1 & $2 / 5$ & $2 / 5$ & $2 / 5$ \\
\hline 3 & $1 / 2$ & $1 / 2$ & $1 / 2$ \\
\hline 2 & $5 / 6$ & $4 / 5$ & $1 / 2$ \\
\hline 23 & $8 / 11$ & $6 / 10$ & $4 / 8$ \\
\hline 29 & $5 / 7$ & $1 / 2$ & $1 / 9$ \\
\hline 28 & $14 / 15$ & $8 / 9$ & $4 / 5$ \\
\hline 17 & $8 / 10$ & $1 / 2$ & $1 / 2$ \\
\hline 6 & $1 / 2$ & $1 / 2$ & $1 / 2$ \\
\hline 27 & $14 / 15$ & $6 / 9$ & $4 / 8$ \\
\hline 22 & $3 / 6$ & $2 / 6$ & $2 / 9$ \\
\hline 8 & $5 / 6$ & $3 / 4$ & $5 / 7$ \\
\hline
\end{tabular}

\begin{tabular}{|c|c|c|c|c|c|c|c|c|c|c|c|}
\hline & $\mathbf{1}$ & $\mathbf{3}$ & $\mathbf{2}$ & $\mathbf{2 3}$ & $\mathbf{2 9}$ & $\mathbf{2 8}$ & $\mathbf{1 7}$ & $\mathbf{6}$ & $\mathbf{2 7}$ & $\mathbf{2 2}$ & $\mathbf{8}$ \\
\hline $\mathbf{1}$ & 1,00 & 1,00 & & 0,25 & $\mathbf{2}, 19$ & $\mathbf{2}, 54$ & 0,85 & 0,86 & & & \\
\hline $\mathbf{2}$ & & & 1,00 & 0,24 & & & & & 0,72 & 0,33 & 0,75 \\
\hline $\mathbf{3}$ & 1,00 & 1,00 & & 0,25 & 0,19 & 0,54 & 0,85 & 0,86 & & & \\
\hline $\mathbf{4}$ & 1,00 & 1,00 & & 0,25 & 0,19 & 0,54 & 0,85 & 0,86 & & & \\
\hline $\mathbf{5}$ & 1,00 & 1,00 & & 0,25 & 0,19 & 0,54 & 0,85 & 0,86 & & & \\
\hline $\mathbf{6}$ & 0,82 & 0,82 & & 0,23 & 0,18 & 0,46 & 0,71 & 1,00 & & & \\
\hline $\mathbf{7}$ & & & 0,81 & 0,23 & & & & & 0,73 & 0,36 & 0,98 \\
\hline $\mathbf{8}$ & & & 0,78 & 0,24 & & & & & 0,74 & 0,36 & 1,00 \\
\hline $\mathbf{9}$ & 0,81 & 0,81 & & 0,28 & 0,18 & 0,62 & 1,00 & 0,71 & & & \\
\hline $\mathbf{1 0}$ & 1,00 & 1,00 & & 0,25 & 0,19 & 0,54 & 0,85 & 0,86 & & & \\
\hline $\mathbf{1 1}$ & 0,87 & 0,87 & & 0,25 & 0,23 & 0,47 & 0,74 & 0,75 & & & \\
\hline $\mathbf{1 2}$ & & & 0,81 & 0,23 & & & & & 0,73 & 0,36 & 0,98 \\
\hline $\mathbf{1 3}$ & 0,86 & 0,86 & & 0,26 & 0,23 & 0,46 & 0,73 & 0,74 & & & \\
\hline $\mathbf{1 4}$ & 0,91 & 0,91 & & 0,23 & 0,22 & 0,49 & 0,78 & 0,78 & & & \\
\hline $\mathbf{1 5}$ & 0,73 & 0,73 & & 0,30 & 0,17 & 0,65 & 0,90 & 0,66 & & & \\
\hline $\mathbf{1 6}$ & 1,00 & 1,00 & & 0,25 & 0,19 & 0,54 & 0,85 & 0,86 & & & \\
\hline $\mathbf{1 7}$ & 0,81 & 0,81 & & 0,28 & 0,18 & 0,62 & 1,00 & 0,71 & & & \\
\hline $\mathbf{1 8}$ & 0,81 & 0,81 & & 0,28 & 0,18 & 0,62 & 1,00 & 0,71 & & & \\
\hline $\mathbf{1 9}$ & & & 0,86 & 0,25 & & & & & 0,77 & 0,36 & 0,87 \\
\hline $\mathbf{2 0}$ & & & 0,89 & 0,25 & & & & & 0,77 & 0,36 & 0,85 \\
\hline $\mathbf{2 1}$ & & & 0,50 & 0,79 & & 0,18 & & & 0,60 & 0,91 & 0,52 \\
\hline $\mathbf{2 2}$ & & & 0,49 & 0,77 & & 0,17 & & & 0,58 & 1,00 & 0,51 \\
\hline $\mathbf{2 3}$ & 0,25 & 0,25 & 0,25 & 1,00 & & 0,29 & 0,29 & 0,24 & 0,31 & 0,55 & 0,24 \\
\hline $\mathbf{2 4}$ & 0,99 & 0,99 & & 0,26 & 0,19 & 0,53 & 0,84 & 0,85 & & & \\
\hline $\mathbf{2 5}$ & 0,98 & 0,98 & & 0,25 & 0,19 & 0,52 & 0,84 & 0,84 & & & \\
\hline $\mathbf{2 6}$ & 0,84 & 0,84 & & 0,21 & 0,23 & 0,53 & 0,78 & 0,75 & & & \\
\hline $\mathbf{2 7}$ & & & 0,72 & 0,31 & & 0,13 & & & 1,00 & 0,40 & 0,72 \\
\hline $\mathbf{2 8}$ & 0,57 & 0,57 & & 0,31 & 0,14 & 1,00 & 0,69 & 0,51 & 0,14 & 0,13 & \\
\hline $\mathbf{2 9}$ & 0,49 & 0,49 & & & 1,00 & 0,34 & 0,49 & 0,49 & & & \\
\hline $\mathbf{3 0}$ & 0,82 & 0,82 & & & 0,26 & 0,44 & 0,70 & 0,70 & & & \\
\hline
\end{tabular}


Table 5. Synthesis of numerical results

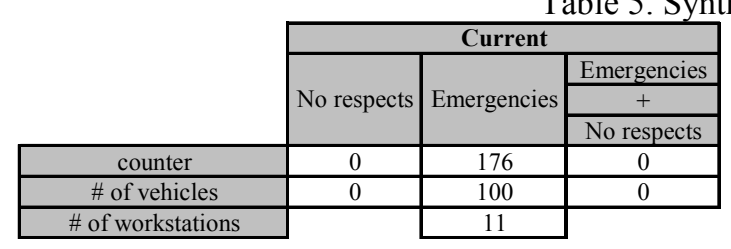

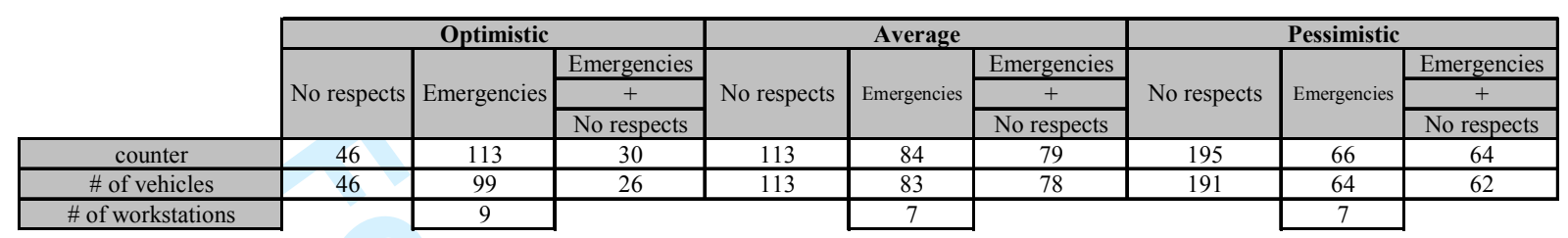

http://mc.manuscriptcentral.com/tprs Email: ijpr@lboro.ac.uk 
Table 6. Zoom on stations number 6 and 13

\begin{tabular}{|c|c|c|c|}
\cline { 2 - 4 } \multicolumn{1}{c|}{} & \multicolumn{3}{c|}{ Pessimistic } \\
\cline { 2 - 4 } & No respects & Emergencies & $\begin{array}{c}\text { emergencies } \\
+ \\
\text { No respects }\end{array}$ \\
\hline W. Station 13 & 59 & 0 & 0 \\
\hline W. Station 6 & 54 & 54 & 54 \\
\hline
\end{tabular}

